\title{
Indolo-naphthyridine-6,13-dione thiophene (INDT) building block for conjugated polymer electronics: Molecular origin of ultra-high n-type mobility
}

Kealan J. Fallon, ${ }^{\ddagger a}$ Nilushi Wijeyasinghe, ${ }^{\ddagger b}$ Eric F. Manley, ${ }^{c, d}$ Stoichko D. Dimitrov, ${ }^{b}$ Syeda A.

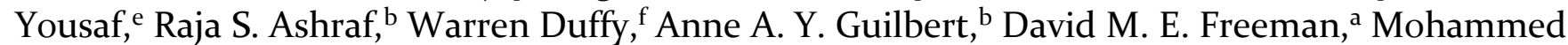
Al-Hashimi, ${ }^{\mathrm{d}}$ Jenny Nelson, ${ }^{\mathrm{b}}$ James R. Durrant, ${ }^{\mathrm{b}}$ Lin X. Chen, ${ }^{\mathrm{c}, \mathrm{d}}$ Iain McCulloch, ${ }^{\mathrm{f}}$ Tobin J. Marks, ${ }^{\mathrm{c}}$ Tracey Clarke, ${ }^{a}$ Thomas D. Anthopoulos ${ }^{b}$ and Hugo Bronstein*a

a Department of Chemistry, University College London, Christopher Ingold Building, London, WC1H oAJ, U.K.

${ }^{\mathrm{b}}$ Centre for Plastic Electronics, Imperial College London, London, SW7 2AZ, U.K.

${ }^{\mathrm{c}}$ Department of Chemistry, Materials Research Center, and Argonne-Northwestern Solar Energy Research Center, Northwestern University, 2145 Sheridan Road, Evanston, Illinois 60208, United States

dChemical Sciences and Engineering Division, Argonne National Laboratory, 970o South Cass Avenue, Lemont, Illinois, 60439

${ }^{\mathrm{d}}$ Department of Chemistry, Texas A\&M University at Qatar, P.O. Box 23874, Doha, Qatar

${ }^{\mathrm{e}}$ Department of Physics, Government College University, Lahore-540oo, Pakistan

f SPERC, King Abdullah University of Science and Technology, Thuwal 23955-690o, Saudi Arabia

\begin{abstract}
Herein we present the synthesis and characterization of four conjugated polymers containing a novel chromophore for organic electronics based on an indigoid structure. These polymers exhibit extremely small band gaps of $\sim \mathbf{1 . 2} \mathrm{eV}$, impressive crystallinity, and extremely high n-type mobility exceeding $3 \mathrm{~cm}^{2} \mathrm{Vs}^{-1}$. The n-type charge carrier mobility can be correlated with the remarkably high crystallinity along the polymer backbone having a correlation length in excess of $20 \mathrm{~nm}$. Theoretical analysis reveals that the novel polymers have highly rigid non-planar geometries demonstrating that backbone planarity is not a pre-requisite for either narrow band-gap materials or ultra-high mobilities. Furthermore the variation in backbone crystallinity is dependent on the choice of co-monomer. OPV device efficiencies up to $4.1 \%$ and charge photo-generation up to $1000 \mathrm{~nm}$ are demonstrated, highlighting the potential of this novel chromophore class in high-performance organic electronics.
\end{abstract}

\section{Introduction}

Recent rapid advances in organic field effect transistors (OFETs) and organic photovoltaics (OPVs) have been propelled primarily by the design, characterization, and understanding of novel conjugated polymers. Small chemical modifications to monomers or building blocks can have major consequences for bulk device transport and photovoltaic efficiency by mechanisms which are incompletely understood. Similarly, there has been much interest in the effects of various comonomer arrays of donor-acceptor (DA) copolymers. Understanding structure-property relationships of conjugated systems is crucial for targeted design of the next generation of high performance organic semiconductors.

Power conversion efficiencies (PCEs) in OPV devices have been climbing steadily in the past few years and efficiencies exceeding $10 \%$ for single-junction and tandem
OPVs have been reported. ${ }^{1-3}$ OFET devices aim for hole $\left(\mu_{\mathrm{h}}\right)$ and electron $\left(\mu_{\mathrm{e}}\right)$ field-effect mobilities above the benchmark of amorphous silicon $\left(1 \mathrm{~cm}^{2} \mathrm{Vs}^{-1}\right)$ in order to compete with their inorganic counterparts and mobilities above this benchmark are considered 'ultra-high'.

There is extensive literature on p-type organic polymers with hole transport $\mu_{\mathrm{h}}>1 \mathrm{~cm}^{2} \mathrm{Vs}^{-1}$. Indeed, many wellknown structural motifs including polythiophene, ${ }^{4,5}$ cyclopentadithiophene (CPDT), ${ }^{6}, \quad 7$ diketopyrrolopyrrole (DPP), ${ }^{8-12}$ isoindigo (iI), ${ }^{13}, 14$ and indacenodithiophene ${ }^{15-17}$ have all displayed ultra-high hole transport in OFETs. Moreover, structural studies reveal that OFET hole mobility is less dependent on long-range structural order in thinfilms, however it is highly dependent on the presence of rigid, extended high-molecular-weight polymer chains allowing charge transport to occur along the polymer backbone and vastly improving interconnectivity between disordered regions. ${ }^{17-20}$ 
As polymer synthesis has steadily improved to afford higher molecular weight polymers which contain planar monomers, it is perhaps unsurprising that most organic structural motifs available to the polymer chemist facilitate high p-type transport. Recently, state-of-the-art p-type organic polymers have reached $\mu_{\mathrm{h}}>10 \mathrm{~cm}^{2} \mathrm{Vs}^{-1}$, approaching the mobility of amorphous metal oxide transistors. ${ }^{21}$

In stark contrast, there are very few examples of OFET devices with ultra-high electron mobility. To the best of our knowledge, there are only 3 families of organic polymers displaying n-type mobility $\mu_{\mathrm{e}}>1 \mathrm{~cm}^{2} \mathrm{Vs}^{-1}$. These either have a polymer backbone based on DPP, naphthalene diimide structures ${ }^{22-26}$ or fused PPV type units ${ }^{27,28}$. Zhao et al. provide an excellent review of the advances in n-type OFET materials. ${ }^{29}$

The exact reasoning behind high electron transport in OFETs remains a debate in the field, however it is widely agreed that the energy of the lowest unoccupied molecular orbital (LUMO) plays a crucial role, since polymers must exhibit high electron affinities to facilitate charge injection. Strong intermolecular orbital overlap of polymer strands in thin-film and high ambient stability are also vital requirements for both electron and hole transport..$^{30}$ However, in general there have been virtually no detailed structure-property relationships reported in the field of high n-type mobility conjugated polymers. Narrow band gap $\left(E_{\mathrm{g}}\right)$ conjugated polymers, $1.1 \leq E_{\mathrm{g}} \leq 2.1 \mathrm{eV}$ have especially low lying LUMO energies making them excellent candidates for n-type OFET materials. They also display optical absorption in the near-IR region of the electromagnetic spectrum, ideal for both tandem and transparent OPV devices.

We recently reported an ultra-narrow bandgap polymer with a novel core structure based on naturally occurring indigo. ${ }^{31}$ Despite the highly planar conformation of indigo, it has found little use in OPV devices due to fast deactivation through internal conversion following photoexcitation: The double-bond character of the central carbon-carbon bond is reduced and the molecule can rapidly lose energy through rotation to effect trans-cis isomerization, ${ }^{32}$ and by single or double proton transfer. 33 These qualities can be overcome by performing annulation on both sides of the indigo molecule to create a new chromophore indolo-naphthyridine-6,13-dione thiophene, INDT, which is rigid and cannot undergo rapid deactivation, thus enhancing suitability for organic electronic applications. ${ }^{31}, 34,35$ Crucially, the implementation of materials using building blocks based on naturally occurring substances can begin to address the issues of sustainability associated with organic electronics. Our previous work utilizing INDT in an organic polymer gave PCEs up to $2.35 \%$ in OPV devices and high ambipolar field effect mobilities $\mu_{\mathrm{h}} / \mu_{\mathrm{e}}$ of $0.23 / 0.48$ $\mathrm{cm}^{2} \mathrm{Vs}^{-1}$ in OFET devices, demonstrating the potential of this novel structure as a thin-film semiconductor.

Herein we report an improved synthesis of this monomer and a series of four polymerizations with conventional comonomers to gain insight into the structure-optical relationships of this relatively unexplored chromophore.
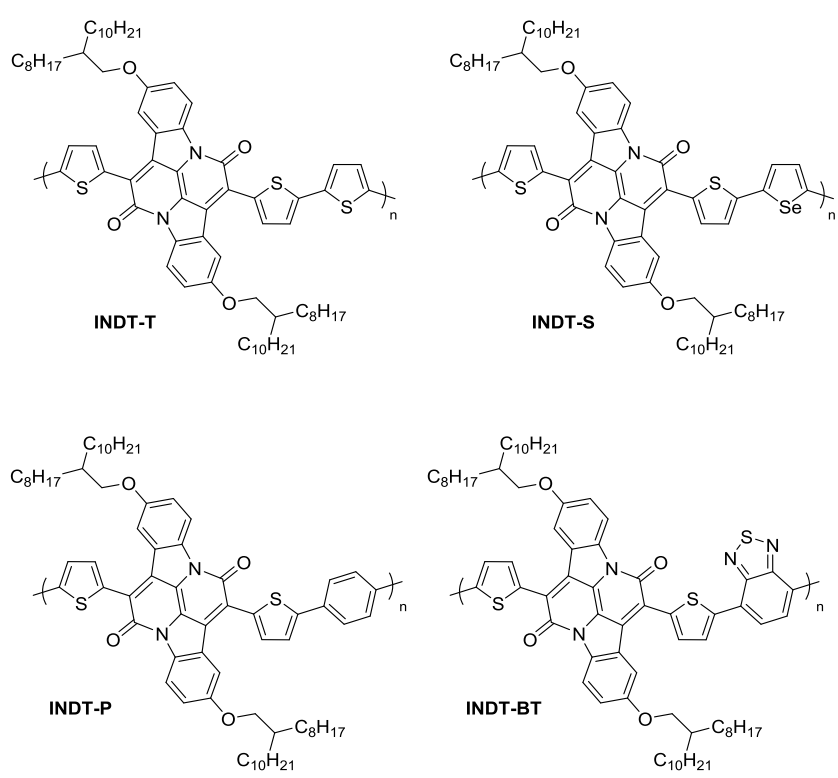

Figure 1. Structures of target polymers following polymerization with thiophene (INDT-T), phenyl (INDT-P), selenophene (INDT-S) and benzothiadiazole (INDT-BT)

\section{Results and Discussion}

Our previously reported synthesis of monomer INDT utilized tetrahydropyran (THP) protecting groups, however the stability of these groups was poor under the acidic annulation reaction conditions (Scheme 1) affording low yields. To improve the total yield of the synthesis we sought a protecting group with greater stability and found that benzyl (Bn) protecting groups had excellent stability in both the basic indigo condensation and acidic IND annulation reactions, affording a twelve-fold improvement in total yield compared to THP strategy.

The full INDT synthesis can be found in the Supporting Information $\left(\mathrm{S}_{1}\right)$ and is summarized in Scheme 1. The initial protection of 5-hydroxy-2-nitrobenzaldehyde with benzyl bromide proceeds in quantitative yield to give 5(benzyloxy)-2-nitrobenzaldehyde. An aldol condensation with acetone gives (E)-5,5'-bis(benzyloxy)-[2,2'biindolinylidene]-3,3'-dione (1). This indigoid can then undergo condensation with 2-thiopheneacetyl chloride to give 2,9-bis(benzyloxy)-7,14-di(thiophen-2-yl)diindolo[3,2,1-de:3',2',1'-ij][1,5]naphthyridine-6,13-dione (2). The benzyl groups of this IND core are stable to general hydrogenation deprotection conditions using Pd on activated charcoal, however near quantitative deprotection was achieved using iodotrimethylsilane. Alkylation with 2-octyldodecanyl chains to improve solubility and subsequent bromination both proceeded in excellent yield to give monomer INDT (4).

Co-polymerization via Stille or Suzuki coupling of INDT with conventional comonomers affords polymers INDT-T, INDT-S, INDT-BT, INDT-P (Figure 1) which were purified by Soxhlet extraction using acetone, then hexane, to remove low molecular weight oligomers, and finally chloroform. Interestingly, INDT-P exhibits poor solubility in chloroform and requires additional Soxhlet purification with chlorobenzene, which is somewhat surprising considering the larger twist the phenyl group usually induces in 

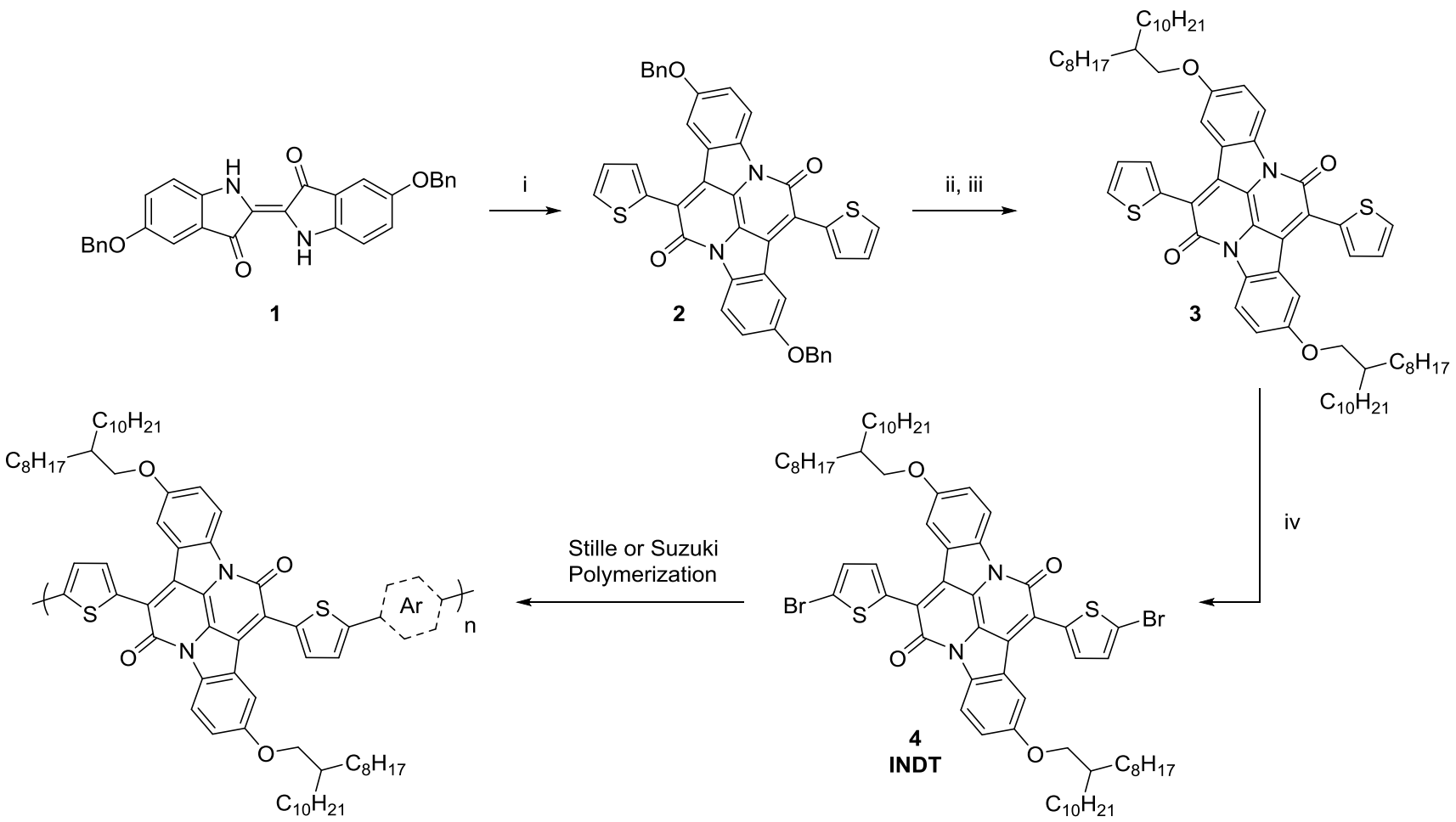

i) 2-thiopheneacetyl chloride, xylene, reflux, $27 \%$ ii) iodotrimethylsilane, $\mathrm{DCM}, 88 \%$ iii) 9-(bromomethyl)nonadecane, $\mathrm{K}_{2} \mathrm{CO}_{3}$, DMF, $60{ }^{\circ} \mathrm{C}, 89 \%$ iv) NBS, DCM, $71 \%$; polymerization conditions and yields in SI (S2)

Table 1. Physical and Optical Properties of INDT Polymers

\begin{tabular}{|l|l|l|l|l|l|l|l|l|l|l|}
\hline Polymer & $\begin{array}{l}\mathrm{M}_{\mathrm{n}} \\
(\mathrm{kDa})^{a}\end{array}$ & $\begin{array}{l}\mathrm{M}_{\mathrm{w}} \\
(\mathrm{kDa})^{a}\end{array}$ & $\mathrm{PDI}^{a}$ & $\lambda_{\max }^{\text {soln }(\mathrm{nm})^{\mathrm{b}}}$ & $\lambda_{\max }^{\text {film }(\mathrm{nm}) \mathrm{c}}$ & $\begin{array}{l}\text { Extinction } \\
\text { Coefficient } \\
\left(\mathrm{M}^{-1} \mathrm{~cm}^{-1}\right)^{\mathrm{b}}\end{array}$ & $\begin{array}{l}\text { HOMO } \\
(\mathrm{eV})^{d}\end{array}$ & $\begin{array}{l}\text { LUMO } \\
(\mathrm{eV})^{e}\end{array}$ & $E_{\mathrm{g}}(\mathrm{eV})^{b}$ & $E_{\mathrm{g}}^{\mathrm{calc}}(\mathrm{eV})^{f}$ \\
\hline INDT-T & 20 & 80 & 4.00 & 802 & 805 & 50912 & -5.02 & -3.76 & 1.26 & 1.32 \\
\hline INDT-S & 25 & 83 & 3.32 & 844 & 849 & 67453 & -4.99 & -3.77 & 1.22 & 1.36 \\
\hline $\begin{array}{l}\text { INDT- } \\
\text { BT }\end{array}$ & 40 & 119 & 2.98 & 826 & 820 & 66780 & -4.97 & -3.74 & 1.23 & 1.31 \\
\hline INDT-P & 29 & 103 & 3.55 & 717 & 736 & 56072 & -5.14 & -3.74 & 1.40 & 1.60 \\
\hline
\end{tabular}

a) Determined by $\mathrm{SEC}(\mathrm{PS})$ using $\mathrm{PhCl}$ as eluent b) $\mathrm{PhCl}$ solution c) Spin-coated from $\mathrm{PhCl} 5 \mathrm{mg} / \mathrm{mL}$ d) Determined by UPS. Data given to two decimal places to illustrate the difference in figures however note that this falls within the error margins ( $\pm 0.1 \mathrm{eV})$ of the experiments e) HOMO + optical energy gap f) Determined by TD-DFT using B3LYP/6-319*

the polymer backbone, though not uncommon and has been seen in other polymers. All of the present polymers display good and comparable molecular weights with slightly high polydispersities as determined by GPC using PS standards and chlorobenzene as eluent. The polydispersities, although slightly high were fairly symmetrical in distribution. Figure $2 \mathrm{a}$ shows the solution (chlorobenzene) and thin film (spin-coated from a $5 \mathrm{mg} / \mathrm{mL}$ solution in chlorobenzene) UV/Vis absorption spectra of the four polymers. The spectra of INDT-T, INDT-S and INDT-BT show broad featureless absorption in the near-IR region whereas the spectrum of INDT-P is considerably blueshifted, arising from a widening of the band gap caused by reduction of the molecular orbital overlap introduced by twisting of the polymer backbone. The polymer extinction coefficients were measured (per repeat unit) and it was found that the value for the BT and S polymers were considerably higher than those of the $\mathrm{T}$ and $\mathrm{P}$ derivatives. The increased extinction coefficients may be due to an increase in co-linearity resulting in greater persistence lengths as has previously been shown in BT and Se containing conjugated polymers. ${ }^{36,37}$ All spectra become somewhat broadened on going from solution to thin films but overall there does not seem to be a significant difference between solution and thin film. 


\section{a}
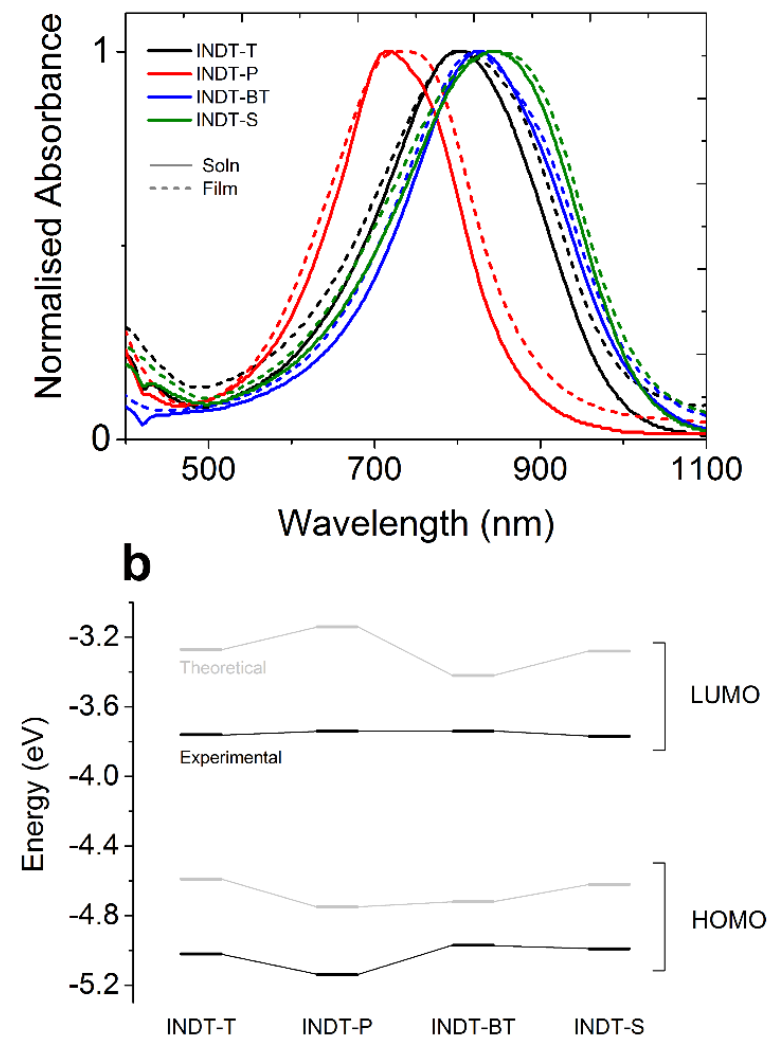

Figure 2. (a) Normalized UV-Vis absorption spectra of the INDT polymers. Solution spectra were recorded in chlorobenzene, and thin films were spun from $5 \mathrm{mg} / \mathrm{mL}$ solutions in chlorobenzene (b) Visualization of band gaps: Theoretical (grey) energy levels were calculated at the $\mathrm{B}_{3} \mathrm{LYP} / 6-31 \mathrm{G}^{*}$ level of theory using DFT for HOMO and time-dependent DFT (TD-DFT) for LUMO. Experimental (black) values for the HOMOs were calculated using UV-PES and the LUMOs resolved by the addition of the optical band-gap to the UV-PES data.

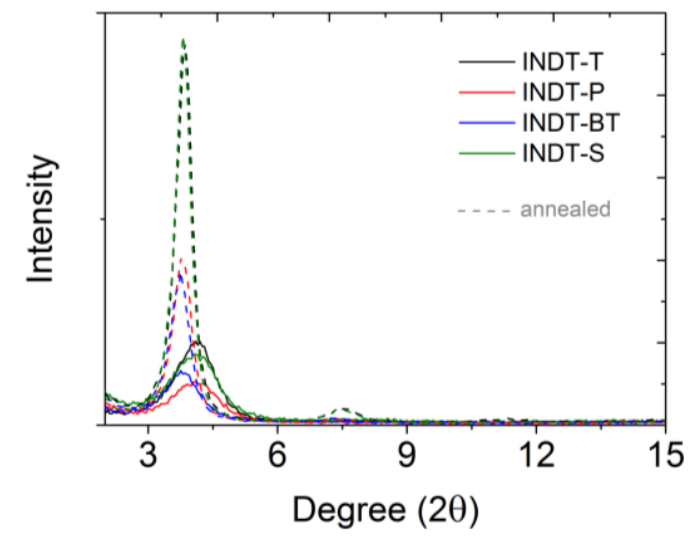

Figure 3. X-ray diffraction of drop-cast INDT polymer films from $5 \mathrm{mg} / \mathrm{mL}$ solutions in chlorobenzene. Annealed films were heated at $100{ }^{\circ} \mathrm{C}$ for $10 \mathrm{~min}$
To investigate the electronic structure of the INDT polymers, density functional theory (DFT) calculations were carried out on model trimers with methoxy substituents. Experimentally, the HOMO energy levels were determined using UV-PES (see $\mathrm{S}_{3}$ ) and the energies of the LUMOs were resolved by the addition of the corresponding optical band gap. The energy levels and band gaps of the four polymers are displayed in Figure $2 \mathrm{~b}$. The trend in experimental and theoretical data for the HOMO energies are generally in good agreement. The comparison of the two sets of data for the LUMO energy levels shows poor alignment between theory and experiment and remarkably, the experimental LUMO energy levels for all four INDT polymers are either 3.7 or $3.8 \mathrm{eV}$, almost identical within experimental error. The molecular orbital distributions of the geometryoptimized structure of each polymer using Gaussian o9 (DFT, B 3 LYP $/ 6-31 \mathrm{G}^{*}$ ) are shown in the supporting information $\left(\mathrm{S}_{4}\right)$. All four polymers have delocalized HOMOs and LUMOs along their backbones suggesting that charge transport in these materials should be efficient.

The influence of annealing temperature on the molecular packing in the polymer thin films was studied by X-ray diffraction (Figure 3 ). Drop-cast polymer thin films show a Bragg reflection at $2 \theta=3.8^{\circ}$, corresponding to the (100) reflection and indicative of a typical lamellar packing distance of $2.3 \mathrm{~nm}$.

Annealing at $100{ }^{\circ} \mathrm{C}$ for 10 min leads to a substantial increase in thin film crystallinity as observed by the increased intensity of the (100) peak. The appearance of the corresponding (200) reflections for INDT-T and INDT-S indicates increased long-range order in these two polymer films. No noticeable changes in film crystallinity are observed after annealing at higher temperatures.

\section{Organic Field Effect Transistors}

Staggered top-gate, bottom-contact (TG-BC) OFETs on glass substrates exhibited superior device performance and lower hysteresis relative to coplanar bottom-gate, bottomcontact (BG-BC) structures on hexamethyldisilazane (HMDS) treated silicon wafer substrates. This is attributed to charge trapping at the interface of the semiconductor and the HMDS-treated silicon dioxide dielectric, combined with the higher parasitic contact resistance $\left(R_{C}\right)$ in the coplanar geometry. $3^{8}$

TG-BC OFET devices were fabricated on solvent-cleaned glass substrates with thermally evaporated source and drain (SD) electrodes. The organic semiconductor layers were spin-cast from chlorobenzene solution $(10 \mathrm{mg} / \mathrm{mL})$ and CYTOP dielectric spin-cast directly onto the polymer thin-films, followed by a thermally evaporated aluminum gate electrode. All devices had channel dimensions of length $(\mathrm{L})=40 \mu \mathrm{m}$ and width $(\mathrm{W})=1000 \mu \mathrm{m}$.

Three types of SD contacts were employed: 1) as-deposited $\mathrm{Au}$ on $\mathrm{Al}$ bilayers for ambipolar charge injection, 2) surface-treated $\mathrm{Au}$ for p-type enhancement, and 3) surface-treated $\mathrm{Al}$ for $\mathrm{n}$-type enhancement. 
Table 2. OFET characteristics of the four INDT-based polymers annealed at $190{ }^{\circ} \mathrm{C}^{a}$

\begin{tabular}{|c|c|c|c|c|c|c|}
\hline Polymer & Type $^{b}$ & $I_{D(\text { lin })}^{\text {on-off }}$ & $I_{D(\text { sat })}^{\text {on-off }}$ & $V_{\text {On(lin) }}[\mathrm{V}]$ & $V_{T h(s a t)}[\mathrm{V}]$ & $\mu_{\mathrm{sat}^{\mathrm{c}}}\left[\mathrm{cm}^{2} \mathrm{Vs}^{-1}\right]$ \\
\hline \multirow{2}{*}{ INDT-P } & $\mathrm{p}$ & $10^{2}$ & $10^{2}$ & -104 & -155 & 0.002 \\
\hline & $\mathrm{n}$ & $10^{3}-10^{4}$ & $10^{3}$ & +10 & +89 & 0.028 \\
\hline \multirow{2}{*}{ INDT-T } & $\mathrm{p}$ & $10^{4}$ & $10^{1}-10^{2}$ & -25 & -92 & 0.29 \\
\hline & $\mathrm{n}$ & $10^{4}-10^{5}$ & $10^{3}-10^{4}$ & -10 & +37 & 0.31 \\
\hline \multirow{2}{*}{ INDT-S } & $\mathrm{p}$ & $10^{3}$ & $10^{1}-10^{2}$ & -40 & -101 & 0.20 \\
\hline & $\mathrm{n}$ & $10^{4}-10^{5}$ & $10^{3}$ & -10 & +74 & 0.99 \\
\hline \multirow{2}{*}{ INDT-BT } & $\mathrm{p}$ & $10^{4}$ & $10^{1}$ & -36 & -121 & 0.52 \\
\hline & $\mathrm{n}$ & $10^{5}$ & $10^{4}$ & -10 & +74 & 3.11 \\
\hline
\end{tabular}

a) $\pm 5{ }^{\circ} \mathrm{C} \mathrm{b}$ ) Parameters extracted from the highest mobility p-type or n-type enhanced devices c) Highest value extracted from a ten-point average of smoothed data
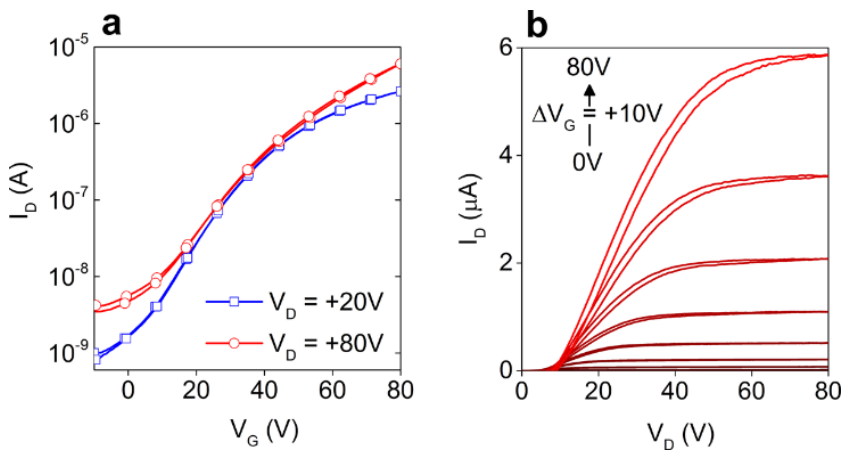

Figure 4. a) Transfer and b) output characteristics of an n-type enhanced INDT-BT OFET annealed at $190^{\circ} \mathrm{C}$ having channel dimensions of length $(\mathrm{L})=40 \mu \mathrm{m}$ and width $(\mathrm{W})=1000 \mu \mathrm{m}$

The work function of air-exposed Au is significantly deepened upon treatment with UV/ozone, facilitating superior hole injection both by removing organic contaminants from the metal surface and forming a native oxide layer. 39,40 The modified work function is a better match to the HOMO energies of the polymer series, lowering the hole injection barrier and reducing $\mathrm{R}_{\mathrm{C}}$. N-type performance can be enhanced by treating $\mathrm{Al}$ with ethoxylated polyethylenimine (PEIE) to reduce the work function to better match the LUMO energies of the polymers, improving electron injection.

OFETs were evaluated after annealing at $100{ }^{\circ} \mathrm{C}$ and 190 ${ }^{\circ} \mathrm{C}$, the latter representing the upper limit of the temperature range for which PEIE treatment is most effective. ${ }^{41}$ OFET parameters were extracted from transfer characteristic data, which demonstrates the gate voltage $\left(V_{G}\right)$ dependence of the source-drain current $\left(I_{D}\right)$, using the standard gradual channel approximation for field-effect transistors. ${ }^{42,} 43$ Linear regime mobility $\left(\mu_{\text {lin }}\right)$ was calculated using the first derivative of the linear regime transfer curve. Threshold voltage $\left(\mathrm{V}_{\mathrm{Th}}\right)$ was extracted by applying a linear fit to the square-root of the saturation regime transfer curve. Figure 4 shows the transfer and output characteristics of an n-type enhanced OFET with INDT-BT annealed at $190{ }^{\circ} \mathrm{C}$. Despite the outlined efforts to reduce charge injection barriers, the s-shaped non-linear output observed at low source-drain voltage $\left(\mathrm{V}_{\mathrm{D}}\right)$ and the lower $\mathrm{V}_{\mathrm{Th}}$ observed at longer channel lengths indicate a large $R_{C}$ and contact limited device performance. ${ }^{44,45} \mathrm{~A}$ complete analysis of the contact resistance in n-type enhanced INDT-BT OFETs is available in the SI $\left(\mathrm{S}_{5.3}\right)$ and demonstrates that $R_{C} \gg 1 M \Omega$ for $V_{G}$ in the linear regime. The standard linear regime operation model does not adequately describe the device physics of this non-ideal OFET, and thus, the extracted $\mu_{\text {lin }}$ is not representative of the bulk property. Furthermore, the standard $V_{\mathrm{Th}}$ extraction procedure typically yields an overestimate in contact-limited devices, and the square-root method of extracting the saturation regime mobility $\left(\mu_{\text {sat }}\right)$ can be unreliable. ${ }^{46,47}$ Values that better represent the bulk properties of the semiconductor were extracted by applying very large voltages to compensate for the large $R_{C}$ and using the second derivative of the saturation regime transfer curve for the $\mu_{\text {sat }}$ calculation. Mobilities were extracted from the appropriate voltage region of the forward voltage sweep. Saturation regime mobility data were smoothed prior to extracting $\mu_{\text {sat }}$ in order to exclude extreme values and yield a conservative estimate. The gate voltage dependence on mobility is shown in the supporting information (S6) and conclusively demonstrates that the mobility is not an overestimation. ${ }^{88,49}$ Gate voltage dependent mobility has been observed in high ptype mobility conjugated polymers and has been suggested to originate from partially filled trap sites. ${ }^{\circ}$ Complete OFET electrical characterization data for devices of each

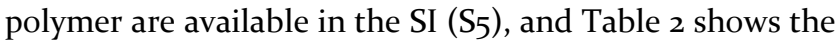
best device results for all four polymers annealed at $190^{\circ} \mathrm{C}$. INDT-T shows balanced ambipolar transport $\left(\mu_{\text {sat }} \sim 0.3 \mathrm{~cm}^{2}\right.$ $\mathrm{Vs}^{-1}$ ), and both INDT-S and -BT show excellent n-type charge transport characteristics and good p-type device performance in single charge polarity enhanced devices. INDT-P devices have relatively smaller maximum $I_{D}$ and yield significantly lower mobilities $\left(\mu_{\text {sat }}<0.1 \mathrm{~cm}^{2} \mathrm{Vs}^{-1}\right)$ due to non-uniformities in the polymer film arising from the lower solubility of INDT-P in chlorobenzene. The poor ptype performance of INDT-P devices can also be attributed to a larger hole injection barrier resulting from the deeper HOMO, as evident from the greater magnitude of the $V_{\text {Th }}$ and the highly non-linear output characteristics at low $V_{D}$. 
Table 3. OFET characteristics of INDT-BT OFET devices

\begin{tabular}{|l|l|l|l|l|l|l|}
\hline $\mathrm{T}^{a}\left[{ }^{\circ} \mathrm{C}\right]$ & \multicolumn{1}{|c|}{ Type } & $I_{D(\text { lin })}^{\text {on-off }}$ & \multicolumn{1}{|c|}{$I_{D(\text { sat })}^{\text {on-off }}$} & $V_{\text {On(lin) }}[\mathrm{V}]$ & $V_{\text {Th(sat })}[\mathrm{V}]$ & $\mu_{\text {sat }}\left[\mathrm{cm}^{2} \mathrm{Vs}^{-1}\right]$ \\
\hline \multirow{3}{*}{100} & $\mathrm{p}^{b}$ & $10^{2}-10^{3}$ & $10^{1}$ & -80 & -150 & 0.18 \\
\cline { 2 - 7 } & $\mathrm{n}^{b}$ & $10^{5}-10^{6}$ & $10^{3}$ & +9 & +83 & 1.05 \\
\hline \multirow{3}{*}{190} & $\mathrm{p}^{b}$ & $10^{3}-10^{4}$ & $10^{1}$ & -44 & -133 & 0.20 \\
\cline { 2 - 7 } & $\mathrm{p}^{c}$ & $10^{4}$ & $10^{1}$ & -36 & -121 & 0.52 \\
\cline { 2 - 7 } & $\mathrm{n}^{b}$ & $10^{5}$ & $10^{2}-10^{3}$ & $+18 \pm 2$ & $+115 \pm 4$ & $1.8 \pm 0.3^{d}(2.3)$ \\
\cline { 2 - 7 } & $\mathrm{n}^{c}$ & $10^{4}-10^{5}$ & $10^{4}$ & $-9 \pm 1$ & $+77 \pm 3$ & $2.8 \pm 0.3^{e}(3.1)$ \\
\hline
\end{tabular}

a) Annealing temperature, $\pm 5^{\circ} \mathrm{C}$ b) Ambipolar device architecture c) Enhanced device architecture d) Mean and S.D. of ten devices e) Mean and S.D. of seven devices. Values in brackets represent the highest mobility recorded for each type of device.
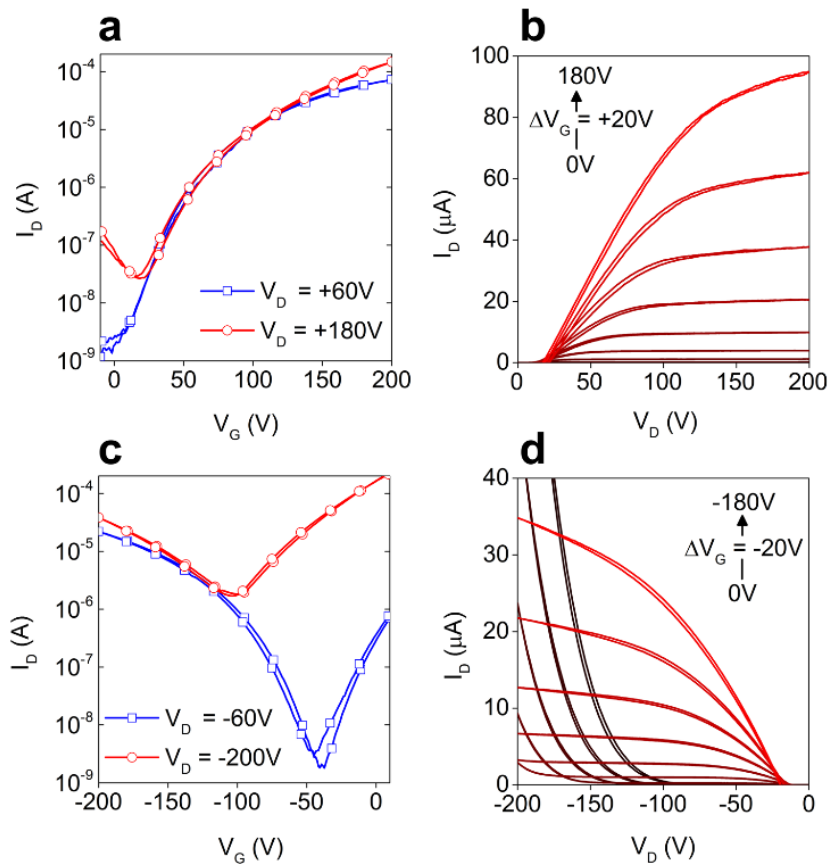

Figure 5. a,c) Transfer and b,d) output characteristics of a,b) n-type enhanced and c,d) p-type enhanced OFET devices with INDT-BT annealed at $190{ }^{\circ} \mathrm{C}$ with channel dimensions of length $(\mathrm{L})=40 \mu \mathrm{m}$ and width $(\mathrm{W})=1000 \mu \mathrm{m}$

Remarkably, the saturation regime electron mobility of INDT-BT (Figure 5) approaches, and in a champion device exceeds, $3 \mathrm{~cm}^{2} \mathrm{Vs}^{-1}$. Table 3 shows a greater part of the data collected on INDT-BT devices. N-type enhanced devices exhibit a mean $\mu_{\text {sat }}$ of $2.8 \pm 0.3 \mathrm{~cm}^{2} \mathrm{Vs}^{-1}$, and the champion device yields an impressive $\mu_{\text {sat }}$ of $3.1 \mathrm{~cm}^{2} \mathrm{Vs}^{-1}$. These results indicate that INDT-BT is one of the highest mobility n-type organic semiconductors reported to date in the peer-reviewed literature. Pleasingly, the performance of INDT-BT OFETs is highly reproducible and values reported herein represent 23 individual devices fabricated identically over an extended period of time.

Extracted $\mu_{\text {lin }}$ values are far smaller than the corresponding $\mu_{\text {sat }}$ values for each device type $\left(\mu_{\text {lin }}<1 \mathrm{~cm}^{2} V^{-1}\right.$ for electrons in INDT-BT OFETs), and $\mathrm{V}_{\mathrm{Th}}$ values are very large (typically, $V_{T h}>|50| V$ ), both providing further evidence of contact-limited performance. 45 Enhancing both p- and n- type OFETs with surface treated SD electrodes both greatly increases the extracted $\mu_{\text {sat }}$ and decreases the magnitude of the extracted $V_{T h}$ demonstrating effective lowering of the respective charge injection barriers. Data from OFETs with INDT-BT annealed at $190{ }^{\circ} \mathrm{C}$ show that in comparison to the ambipolar OFET devices with bilayer SD electrodes $\left(\mu_{\text {sat }}=1.8 \pm 0.3 \mathrm{~cm}^{2} \mathrm{Vs}^{-1}\right)$, devices with PEIE-treated Al SD showed far superior $n$-type performance $\left(\mu_{\text {sat }}=2.8 \pm 0.3\right.$ $\left.\mathrm{cm}^{2} \mathrm{Vs}^{-1}\right)$ relative to devices with untreated $\mathrm{Al} \mathrm{SD}\left(\mu_{\mathrm{sat}}=1.9\right.$ $\left.\pm 0.3 \mathrm{~cm}^{2} \mathrm{Vs}^{-1}\right)$. Hence, the dramatically improved n-type performance of the enhanced devices can be attributed primarily to the presence of the PEIE electron injection layer. A full discussion on the trap density and environmental stability of the devices is included in the supporting information ( 55.4 and $\left.\mathrm{S}_{5.5}\right)$.

The almost complete similarity in LUMO energies of these four polymers provides a unique chance to examine structure/optoelectronic relationships of these polymers irrespective of LUMO energy. We were keen to investigate whether the superior electron transport properties exhibited by INDT-BT arises from morphological features. Figure 6 shows tapping-mode atomic force microscopy (AFM) images of $5 \mu \mathrm{m}^{2}$ polymer thin-films on glass substrates prepared identically to the semiconducting layer in the above OFETs. Phase information, surface roughness distributions and higher resolution $1 \mu \mathrm{m}^{2}$ scans are provided in the SI $\left(\mathrm{S}_{7}\right)$.

When viewed with AFM (Figure 6), the morphology of the INDT-BT films differ significantly from the other polymers: INDT-T, INDT-S and INDT-P films all exhibit a relatively flat $(\mathrm{RMS}=2.5-3.5 \mathrm{~nm})$ polycrystalline structure, while INDT-BT forms thin-films with high surface roughness $(\mathrm{RMS}=9.1 \mathrm{~nm}$ ) that contain a network of smooth (RMS = 1-2 $\mathrm{nm}$ ) ribbon-like features. The ultra-high electron transport of INDT-BT suggests that its thin-films are not amorphous, and are instead highly ordered crystalline systems. Grazing incidence wide-angle x-ray scattering (GIWAXS) was performed to examine the differing intermolecular interactions in the thin-film of INDT-T, INDTS and INDT-BT. The $2 \mathrm{D}$ images are presented in the SI (S8) and the out-of-plane $\left(\mathrm{q}_{\mathrm{z}}\right)$ and in-plane $\left(\mathrm{q}_{\mathrm{xy}}\right)$ line cuts are presented in Figure 7. 
Table 4. GIWAXS correlation lengths and $d$-spacings of diffraction planes of INDT polymer thin-films

\begin{tabular}{|c|c|c|c|c|c|c|c|}
\hline \multirow{2}{*}{ Polymer } & \multirow{2}{*}{$\begin{array}{l}\text { Edge-on }{ }^{\mathrm{a}} \\
\text { Face-on }^{\mathrm{b}}\end{array}$} & \multicolumn{3}{|c|}{ d-spacing $(\AA)$} & \multicolumn{3}{|c|}{ Correlation length (nm) } \\
\hline & & $(100)$ & (010) & $(001)^{c}$ & $(100)$ & (010) & $(001)^{c}$ \\
\hline \multirow{2}{*}{ INDT-BT } & Edge-on & 23.3 & 3.66 & 17.8 & 13 & 2.7 & 23 \\
\hline & Face-on & 26.5 & 3.5 & - & 9.9 & 3.3 & - \\
\hline \multirow{2}{*}{ INDT-S } & Edge-on & 22.8 & 3.62 & $17 \cdot 3$ & 13 & 2.7 & 9.6 \\
\hline & Face-on & 27.2 & - & - & 4.9 & - & - \\
\hline \multirow{2}{*}{ INDT-T } & Edge-on & 22.4 & 3.66 & $17 \cdot 5$ & 15 & 2.5 & 11.8 \\
\hline & Face-on & 22.4 & - & - & 2.1 & - & - \\
\hline
\end{tabular}

a) Edge-on domains include out-of-plane $\left(\mathrm{q}_{\mathrm{z}}\right)$ (100) peaks and in-plane $\left(\mathrm{q}_{\mathrm{xy}}\right)$ (o10) peaks b) Face-on domains include in-plane ( $\left.\mathrm{q}_{\mathrm{xy}}\right)$ (100) peaks and out-of-plane $\left(\mathrm{q}_{\mathrm{z}}\right)(\mathrm{o10})$ peaks $\mathrm{c}$ ) (oo1) peaks do not distinguish between an edge-on or face-on orientation
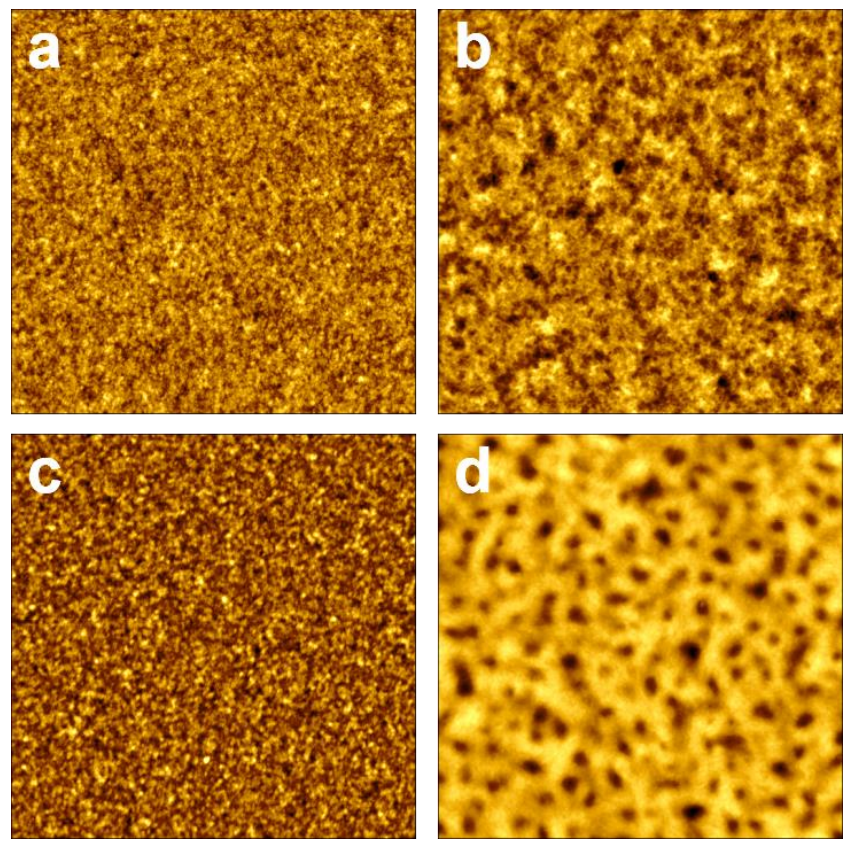

Figure 6 Tapping-mode AFM topography of $5 \mu \mathrm{m}^{2}$ samples of INDT polymer films spin-cast onto glass from chlorobenzene solutions (10 $\mathrm{mg} / \mathrm{mL})$ and annealed at $190{ }^{\circ} \mathrm{C}$. a) INDT-T b) INDT-S c) INDT-P d) INDT-BT

Crystalline correlation lengths (CCL) and $d$-spacings of the three polymers calculated from the GIWAXS data are presented in Table 4 and CCLs were calculated using a Scherrer analysis modified for a $2 \mathrm{D}$ detector. ${ }^{51}$ In general, the three polymers have similar crystallinities and orientations; however there are a few key differences that help explain their performance variations.

In the out-of-plane $\left(\mathrm{q}_{\mathrm{z}}\right)$ cuts (Figure $\left.7 \mathrm{a}\right)$, all three polymers show significant edge-on lamellar ordering with (100), (200), (300) and even (400) peaks clearly visible. The $d$-spacing and CCLs for these edge-on lamellar domains are all similar as well; indicating there is comparative sidechain based ordering in these three polymers.

Additionally INDT-BT demonstrates a clear out-ofplane $\pi-\pi$ stacking (010) peak, indicating it also has faceon $\pi-\pi$ stacking crystallites, in contrast to the other two polymers. The in-plane $\left(q_{x y}\right)$ line cuts (Figure $7 \mathrm{~b}$ ) for all three polymers exhibit edge-on (o10) peaks, however
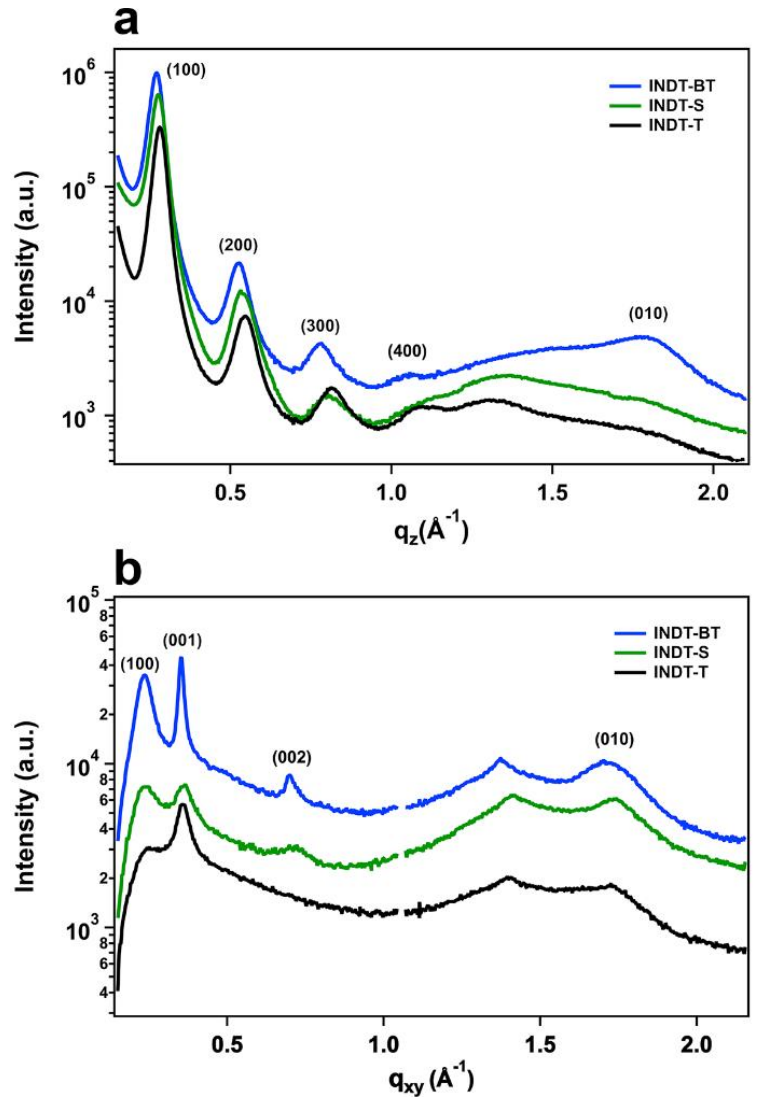

Figure 7. Grazing incidence wide-angle x-ray scattering line cuts a) out-of-plane (qz) b) in-plane (qxy). The line cuts are offset for clarity.

there is a demonstrative reduction in peak intensity in the progression INDT-BT to INDT-S to INDT-T. Additionally, all three polymers show some indication of face-on (100) domains, however there is a great reduction in intensity and CCL of this domains on going from INDT-BT to INDT-S to INDT-T as shown in Table 4. It appears that INDT-BT shows some balance between edge-on and faceon domains while INDT-S and INDT-T greatly favor the edge-on orientation. Crucially, there is a significant difference in the polymer (oo1) and (0o2) peaks, which correspond to planes resulting from repeat polymer units in an ordered chain backbone (Figure 8) 


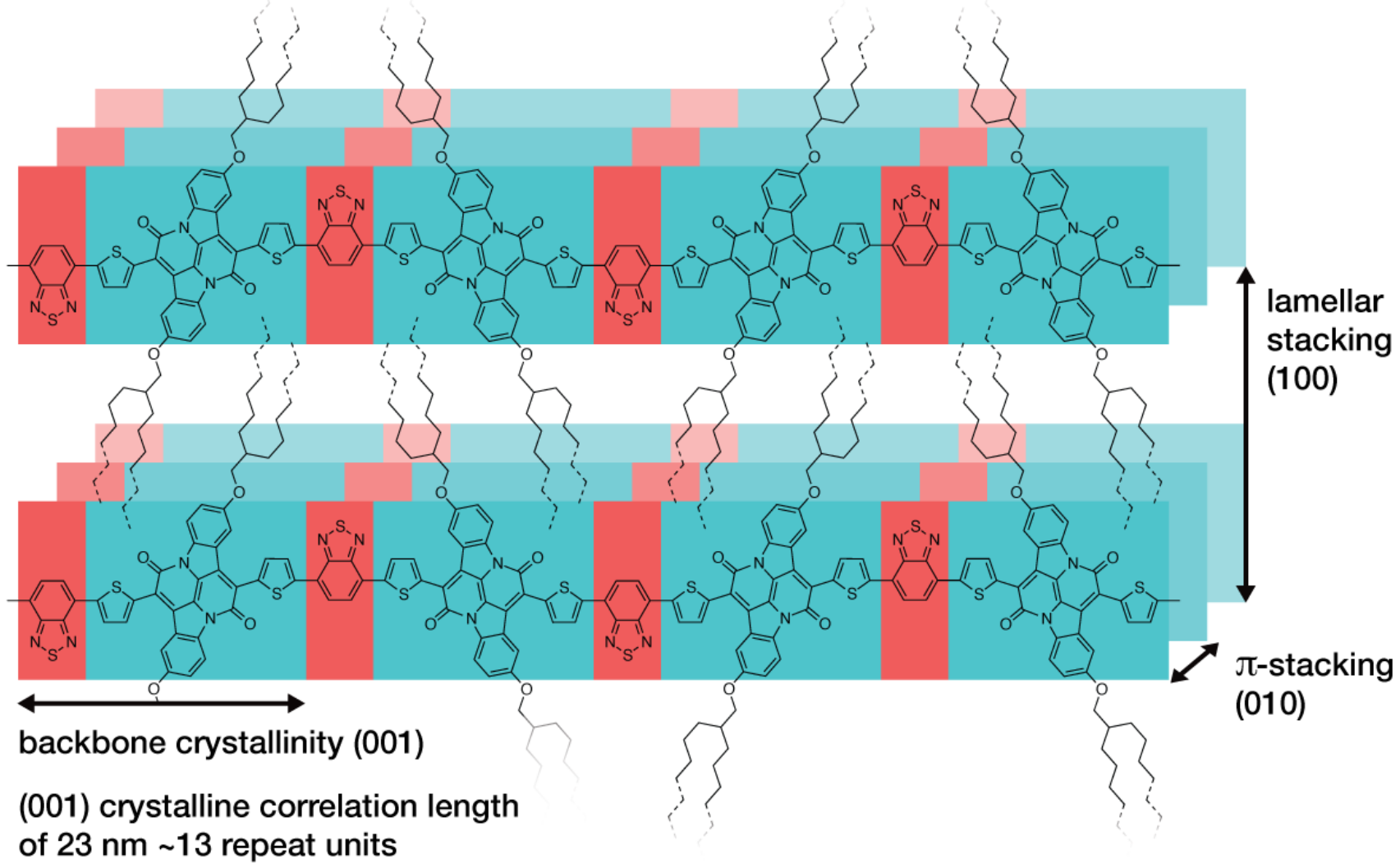

Figure 8. Visualization of the GIWAXS results of the thin-film crystallinity of INDT-BT

These peaks indicate the relative degree to which the polymer is forming straight chains in the film, a highly beneficial quality for charge transport. ${ }^{22}$ The (oo1) peak $d$ spacings are in good accordance with the geometry-optimized size of a repeat unit. The large CCL in all three polymers, but especially in INDT-BT indicates strong straight chain ordering. The CCL of $23 \mathrm{~nm}$ for INDT-BT corresponds to 13 repeat units, a remarkable level of straight chain ordering for a polymer of this design. INDT-BT exhibits a sharp (001) peak and a sharp (002) second order reflection while INDT-S exhibits a clear (oo1) peak and a broad, but clear second order reflection. INDT-T exhibits a (oo1) peak but no second order reflection indicating that while it does have strong periodicity along the chain backbone, including a Scherrer analysis-derived CCL slightly higher than INDT-S, the lack of a (oO2) indicates the ordering is not as strong as in the other two polymers.

We believe the highly ordered straight chain backbone properties of INDT-BT are the source of its ultra-high electron transport properties. These results correlate with similar findings for high p-type mobility conjugated polymers and demonstrate how high polymer backbone ordering is crucial for high charge transport. ${ }^{17}$ It is important to discuss the implications of these results in the greater context of conjugated polymer design. Typically, introduction of selenophene or benzothiadiazole moieties into a conjugated polymer backbone has been a successful strategy to enhance charge transporting characteristics, in particular n-type mobility. ${ }^{53-56}$ The apparent increase in n-type mobility in such cases may have resulted from the lowering of the LUMO which facilitates charge injection. However, in our case we find that there is very little difference in measured LUMO energy between the T, S, and BT containing conjugated polymers, yet we still see significantly enhanced n-type charge transport, due to the increased ordering along the polymer backbone. The fact that we are not modifying the INDT monomer unit, but only changing the co-monomer from $\mathrm{T}$ to $\mathrm{S}$ to $\mathrm{BT}$ means that the increase in backbone ordering must originate solely from this modification. This suggests that both benzothiadiazole and selenophene (the former more than the latter) may have an inherent ability to induce order along the polymer backbone. Therefore it is possible that the increase in mobility that is commonly observed when introducing either S or BT units is not solely due to electronic effects on the LUMO but also to a subtle increase in order along the polymer backbone resulting from intra-molecular rigidification of the backbone structure ${ }^{57}$ or increased inter-molecular stacking interactions ${ }^{7}$.

To investigate the origin of the rigidity of the polymer backbones we examined the theoretical degrees of rotational freedom along the novel polymers (Figure 9). Initially we set out to understand the origin of the increased backbone ordering (and hence mobility) of the BT vs $\mathrm{S}$ and $\mathrm{T}$ co-monomer units $\left(\theta_{\mathrm{B}}\right)$. Torsional potentials of each comonomer-thiophene dimer were calculated at $10^{\circ}$ intervals, holding the connecting dihedral angle fixed whilst performing geometry optimization on all remaining degrees of freedom at the $\mathrm{B}_{3} \mathrm{LYP} / 6-31+\mathrm{G}^{* *}$ level of theory (see SI S9). The optimized geometries attained using DFT were 
therefore taken as input geometries for single point energy calculations at the $\mathrm{MP}_{2} / \mathrm{cc}-\mathrm{pVTZ}$ level of theory ${ }^{8}$ and are plotted in Figure 10.

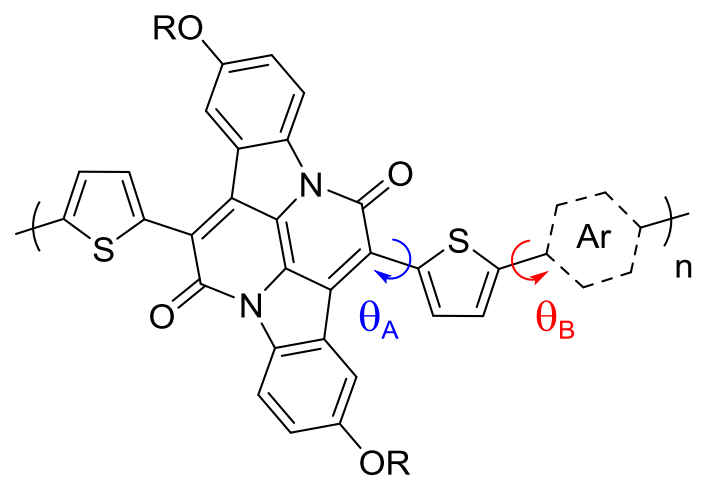

Figure 9. Visualisation of the sites of rotational freedom along the INDT-X polymer backbone occurring at the connecting bonds of IND to thiophene $\left(\theta_{\mathrm{A}}\right)$ and thiophene to the different co-monomers $\left(\theta_{\mathrm{B}}\right)$

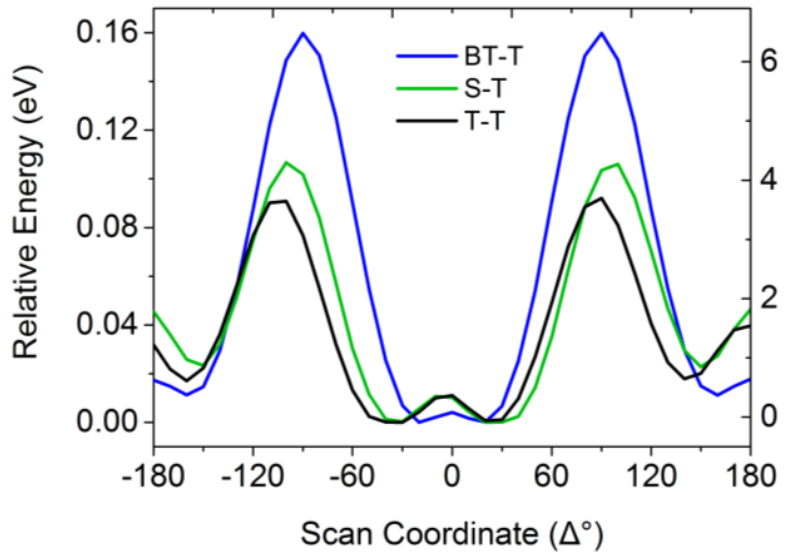

Figure 10. Potential energy surfaces (MP2/cc-pVTZ) of dihedral angles $\left(\theta_{\mathrm{B}}\right)$ of dimers of thiophene with benzothiadiazole (BT), selenophene (S) and thiophene $(\mathrm{T})$ where $\mathrm{o}^{\circ}$ corresponds to planar structures with heteroatoms in trans-conformation.

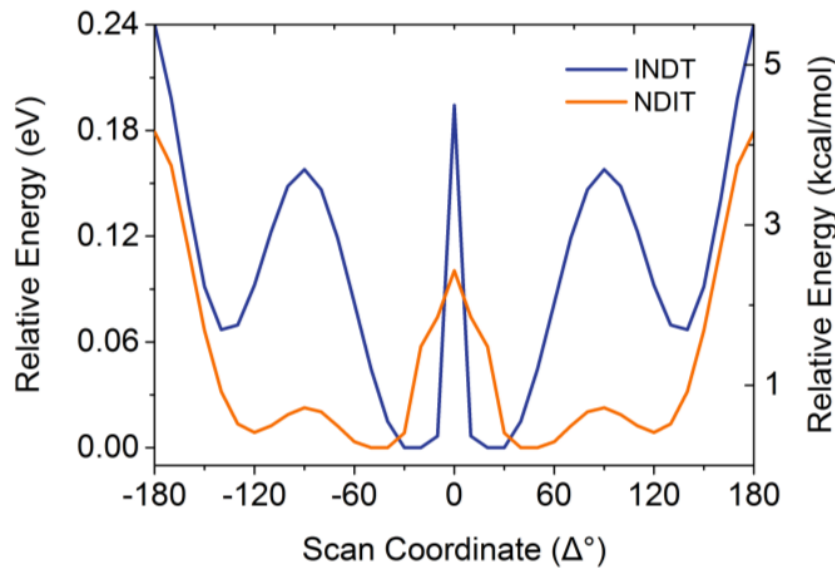

Figure 11. Potential energy surfaces (MP2/cc-pVTZ) of dihedral angles $\left(\theta_{\mathrm{A}}\right)$ of dimers of thiophene with IND and NDI where $\mathrm{O}^{\circ}$ corresponds to fully planar structures with heteroatoms in syn-conformation.
All three dimers are most stable in their trans orientation as expected, although the completely planar geometry is slightly disfavored. The three different sub-units all show rotational energy barriers with significantly higher maxima for the BT-T than for S-T or T-T. The degree of restriction of rotation for the dimers follows the trend BT $>\mathrm{S}>\mathrm{T}$, which matches the trend in experimental n-type transport as a function of polymer backbone ordering, suggesting how lower degrees of rotational freedom along the polymer backbone gives rise to a higher degree of ordering. The high torsional potential of the BT-T couple has previously been linked to the origin of high p-type mobility in conjugated polymers. ${ }^{77}$ The natural ability of benzothiadiazole to increase rigidity and therefore backbone ordering in a conjugated polymer chains thus allowing efficient charge transport may begin to explain why this heterocyclic unit has consistently been present in the highest performing polymers for organic electronics. It must also be mentioned that the potential for intra-molecular dipolar ordering of BT units can also assist polymer chain packing. However, these results further suggest that the commonly seen increased mobility of selenophene containing polymers over their thiophene analogues is, at least, in part due to reduced torsional disorder.

Figure 11 shows the results of the same calculations of the indolo-naphthyridine-6,13-dione-thiophene (INDT) dehdral $\left(\theta_{\mathrm{A}}\right)$. Large destabilizing interactions for planar conformations $\left(\theta=0^{\circ} / \pm 180^{\circ}\right)$, arising from steric interactions between either the $\mathrm{S}-\mathrm{O}$ or $\mathrm{H}-\mathrm{O}$ atoms are clearly visible. The lowest energy conformation is one where the INDT unit is non-planar and has a dihedral angle of approximately $30^{\circ}$. At perpendicular geometries $\left(\theta= \pm 90^{\circ}\right)$ another energetic maxima arising from disruption of the conjugation. The outcome of this is that the lowest energy conformation of the INDT core is narrowly flanked by two high energy barriers resulting in a very small amount of torsional disorder and consequently gives rise to the unusually high amount of polymer backbone order we observe experimentally. At the MP2 level of theory, INDT presents some degree of "conformational locking" and the degree of "conformational locking" appears to be higher in the case of the INDT-BT analogue.

The torsional potentials of naphthalene diimide-thiophene (NDIT), a repeat unit in well-established high ntype materials, was also considered (Figure 11). NDIThiophene containing conjugated polymers are the only other class of materials which display high n-type mobility, yet possess a non-planar backbone. 29, 59-61 Furthermore, it is one of the very few other conjugated polymer families which displays long range order along the polymer backbone. ${ }^{62}$ Both NDIT and INDT are energetically unstable at fully planar geometries and in general show similar features. However it can clearly be seen that at MP2 and B3LYP (supporting information S9) level of theory the rotational barriers for NDIT are lower than those for INDT. This is a possible explanation for the higher n-type mobility of our novel series of materials over the well-established NDI containing polymers. ${ }^{63}$ By thermally populating the energetic profile it is clear that the energetic disorder in INDT is significantly reduced relative to NDIT (Supporting 
information S10). However it must be noted that in the case of NDI2OD-2T (the most well-known high n-type mobility polymer) there are fewer degrees of rotational freedom overall (a total of 3 dihedrals per repeat unit) in comparison to INDT-BT (a total of 4 dihedrals per repeat unit). Finally, we note that the molecules in the calculations are isolated in nature and that solid state packing can have an important role in determining backbone conformation potentially overcoming the computationally observed energetic barriers. However, the similarity of the solution and thin film UV-Vis spectrum which does not display any significant red-shift or other signs of drastic changes to the backbone conformation means that we do not believe that the observed torsional barriers play an important role in these polymers.

In order to further understand the difference in rotational energy barriers between INDT and NDIT we looked at the distribution of the HOMO on going from the lowest energy to the fully orthogonal conformation (Figure 12). In the case of NDIT we find that on increasing the dihedral the HOMO goes from being delocalized across the entire NDIT unit to being localized predominantly on the thiophene, as would be expected from its donor-acceptor type characteristics (Figure 12, B \& D). It is possible that increasing the amount of charge-transfer like interactions could have a stabilizing effect on this conformation. However, there is also a clear contribution to the HOMO from the oxygen atom of the NDI unit potentially indicating some kind of stabilizing lone pair-arene interaction. ${ }^{64}$ In stark contrast, on increasing the dihedral for the INDT unit the HOMO remarkably becomes fully localized on the IND core (Figure 12, A \& C). This is counter to what one might expect from the traditional view of D-A type conjugated polymers. Therefore, the relatively high barrier for rotation arises solely from the energetic cost of reduced conjugation.

To investigate the unusual orbital distribution of the twisted geometry in INDT we can construct basic MO diagrams using DFT/TD-DFT for NDIT and INDT (Figure Si1). NDIT displays conventional donor-acceptor orbital hybridization. INDT however shows unusual characteristics in that the LUMO of the IND core is not below that of T implying that INDT cannot be classified as a typical "acceptor" unit. Instead, the narrow band-gap observed in the novel polymers is more a result of the inherent narrow energy levels of IND, which is then further narrowed through conjugation, rather than the traditional picture of orbital hybridization. The origin of the narrow band-gap can be attributed to the indigoid like core, which has similar electronic characteristics to mercocyanine dyes. ${ }^{65}$ However, we note that when including the entire T-T-T (or alternative) repeat unit into the $\mathrm{MO}$ diagram IND does take on some 'acceptor' like properties.

Overall, these studies suggest that the IND based polymers are a remarkable addition to the field of organic electronics. In contrast to the vast majority of current materials we have demonstrated that it is possible to achieve ultra-high mobilities and very narrow band-gap materials from non-planar conjugated polymers. The key to the mo- bility appears to stem from the conformational lock imposed by the nearby carbonyl group and unfavorable perpendicular geometry which allows for the observed high backbone ordering. The inherent narrow band-gap of the IND core means that extremely narrow band-gap conjugated polymers can be achieved without the need for planarity or the D-A orbital hybridization approach, thus offering a new route to low band-gap conjugated polymers.
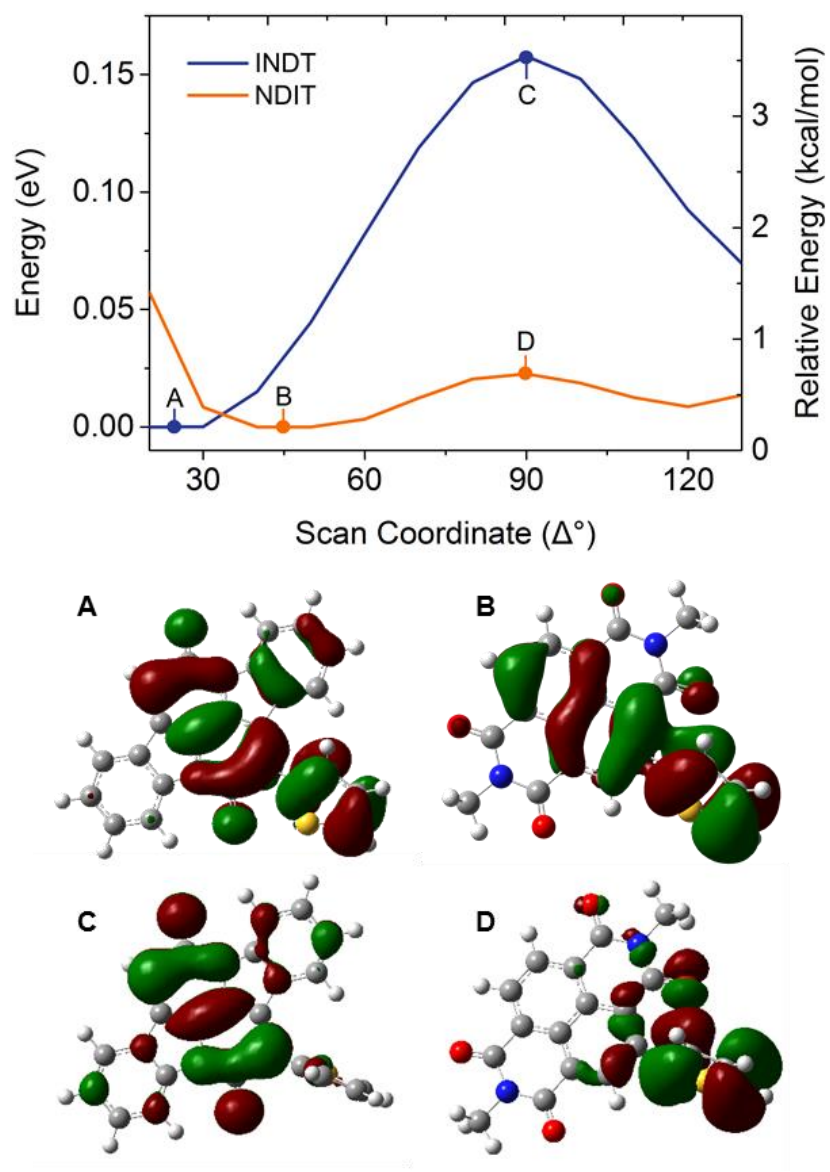

Figure 12. Partial potential energy surfaces shown in figure $x$ between $20^{\circ}<\theta<140^{\circ}$ showing the predicted (MP2/cc-pVTZ) HOMO at lowest (A \& B) and highest potential energies (C \& D)

\section{Organic Solar Cells}

To expand the scope of the investigation, conventionally structured OPV devices were fabricated using the present polymers and $\mathrm{PC}_{71} \mathrm{BM}$, spin-coated from a $4: 1 \mathrm{CHCl}_{3}: \mathrm{ODCB}$ solution $(10 \mathrm{mg} / \mathrm{mL})$. J-V plots are shown in Figure 13 and device data are tabulated in Table 5 . We previously reported the maximum efficiency of INDT-T in a conventionally structured OPV device to be $2.3 \%$; Using the higher molecule weight material, the open circuit voltage $\left(\mathrm{V}_{\mathrm{OC}}\right)$ was measured to be $0.6 \mathrm{~V}$, with significant improvements to the short circuit current (JSC) and the fill factor (FF), resulting in an overall device efficiency of 3.5\%. The increase is likely due to the increased molecular weight resulting in an improved bulk heterojunction (BHJ) morphology. INDT-S devices have a lower $\mathrm{V}_{\mathrm{OC}}$, in line with the 
raised HOMO observed experimentally, and an overall device efficiency of $3.1 \%$. The reasonably high FFs for both INDT-T and INDT-S indicate that both materials are performing correctly in the BHJ devices.

Although the efficiency of the devices are modest it should be noted that these are some of the highest values reported for materials with such narrow band-gaps. ${ }^{66}$ INDT-P has a significantly larger $\mathrm{V}_{\mathrm{oc}}$, again in agreement with the deeper HOMO caused by the twisting of the phenyl group in the polymer backbone, however the FF and $\mathrm{J}_{\mathrm{sc}}$ are both low. INDT-P is relatively insoluble in chlorobenzene and obtaining good quality films was not possible. Thus it is not possible to determine whether the reduced performance is due to electronic or morphological factors. Finally, INDT-BT did not perform well in OPV devices in part due to reduced performance in all three figures of merit, especially $\mathrm{J}_{\mathrm{sc}}$. The lower $\mathrm{V}_{\mathrm{OC}}$ is likely contributed by the higher HOMO in INDT-BT reducing the cross-gap with the fullerene acceptor. The reduced FF and $\mathrm{J}_{\mathrm{SC}}$ are most likely products of the high crystallinity that affords such high OFET mobilities, but in this case, the large crystalline domains suppress intermixing between the donor and acceptor phases, leading to reduced photocurrent generation.

Table 5. OPV Device Characteristics of INDT-Based Solar Cells

\begin{tabular}{|l|l|l|l|l|}
\hline Polymer & $\mathrm{V}_{\mathrm{OC}}(\mathrm{V})$ & $\begin{array}{l}\mathrm{J}_{\mathrm{sc}} \\
\left(\mathrm{mA} \mathrm{cm}{ }^{-2}\right)\end{array}$ & FF & PCE (\%) \\
\hline INDT-T & 0.60 & 9.1 & 0.64 & 3.5 \\
\hline INDT-S & 0.56 & 8.9 & 0.61 & 3.1 \\
\hline INDT-P & 0.69 & 6.0 & 0.43 & 1.8 \\
\hline INDT-BT & 0.57 & 4.4 & 0.53 & 1.31 \\
\hline
\end{tabular}

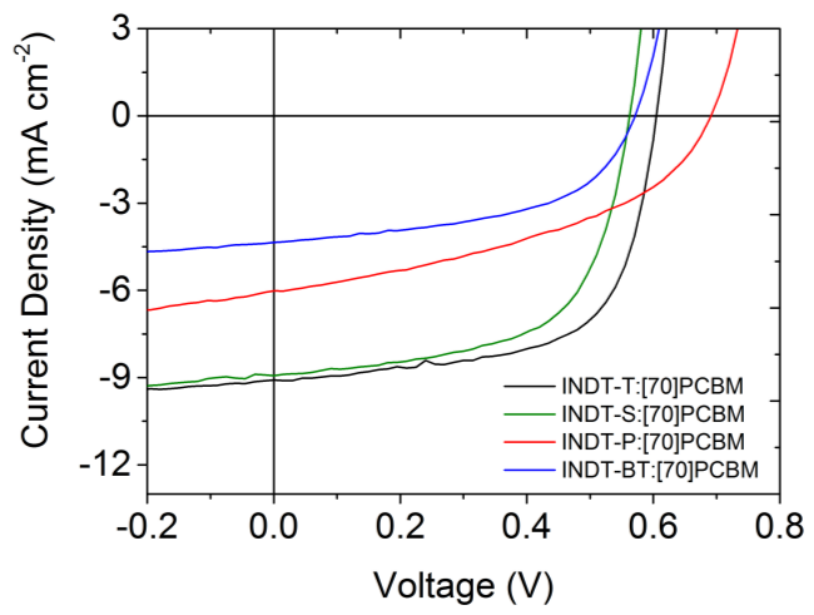

Figure 13. J-V characteristics of polymer:PC $71 B M$ (1:2) solar cells

The effect of varying fullerene blend ratio in INDT-T and INDT-S based OPV devices was investigated as both these materials show promise for near-IR based solar cells. The
EQEs and resulting data are shown in Figure 14 and Table 6. It can clearly be seen that for both INDT-T and INDT-S increasing the fullerene content leads to increased device performance. For both polymers, $\mathrm{V}_{\mathrm{OC}}$ and FF remain relatively constant on increasing fullerene concentration, but a significant increase in $\mathrm{J}_{\mathrm{SC}}$ is observed. For INDT-T, a champion device efficiency of $4.1 \%$ was obtained, whereas for INDT-S, although a similar $\mathrm{J}_{\mathrm{SC}}$ of $\sim 10 \mathrm{~mA} \mathrm{~cm} \mathrm{~m}^{-2}$ being obtained, the lower $\mathrm{V}_{\mathrm{OC}}$ led to slightly lower overall PCEs. The external quantum efficiencies (EQEs) of both polymer devices are of considerable interest. Although it is clear that the majority of the photocurrent originates from the fullerene absorption $(\sim 450 \mathrm{~nm})$, there is a clear and significant contribution from the polymer absorption. Remarkably, as the fullerene concentration is increased, it can clearly be seen that the increasing photocurrent is in part due to a greater contribution from the polymer absorption and EQE values in excess of 0.2 are observed at wavelengths up to $900 \mathrm{~nm}$. Considering the ultra-low band-gaps of these polymers and relatively large $V_{O C}$ of the OPV devices, the fact that relatively efficient charge photo-generation is observed at all is remarkable. It can be expected that the driving force for charge separation $\left(\Delta G_{C S}\right)$ is very low and indeed, taking the most commonly quoted electron affinity of $\mathrm{PC}_{71} \mathrm{BM}, 3.7 \mathrm{eV}$, the LUMO levels of the donor and acceptor are almost isoenergetic, implying virtually zero $\Delta \mathrm{G}_{\mathrm{cs}}$. Despite this, all contribution to the photocurrent above $700 \mathrm{~nm}$ results from a distinct contribution from polymer absorption.

Table 6. OPV Device Characteristics of INDT-T and INDT-S Solar Cells with Different Fullerene Blends

\begin{tabular}{|l|l|l|l|l|l|}
\hline Polymer & $\mathrm{D}: \mathrm{A}^{a}$ & $\begin{array}{l}\mathrm{J}_{\mathrm{sc}} \\
\left(\mathrm{mA} \mathrm{cm} \mathrm{cm}^{-2}\right)\end{array}$ & $\mathrm{V}_{\mathrm{oc}}(\mathrm{V})$ & $\mathrm{FF}$ & $\begin{array}{l}\text { PCE } \\
(\%)\end{array}$ \\
\hline \multirow{3}{*}{ INDT-T } & $1: 2$ & 0.60 & 9.1 & 0.64 & 3.5 \\
\cline { 2 - 6 } & $1: 3$ & 0.61 & 10.0 & 0.66 & 4.0 \\
\cline { 2 - 6 } & $1: 4$ & 0.61 & 10.2 & 0.66 & 4.1 \\
\hline \multirow{2}{*}{ INDT-S } & $1: 2$ & 0.56 & 8.9 & 0.61 & 3.1 \\
\cline { 2 - 6 } & $1: 3$ & 0.57 & 10.3 & 0.60 & 3.5 \\
\hline
\end{tabular}

a) Ratio of polymer donor (D) to fullerene acceptor (A)
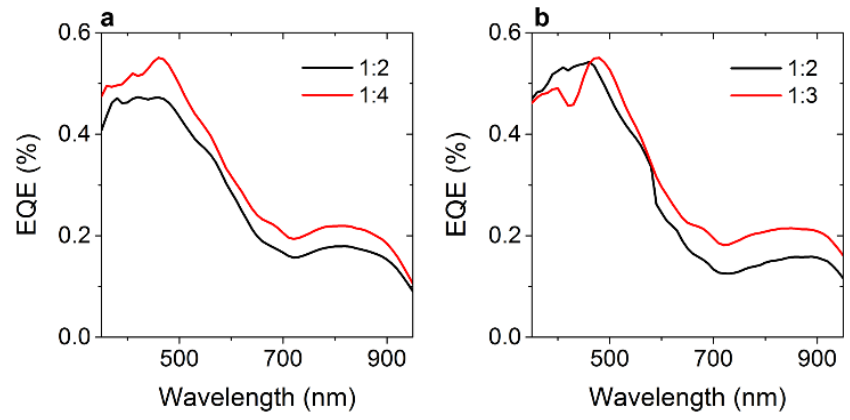

Figure 14. EQEs of solar cells of a) INDT-T and b) INDT-S with varying polymer: $\mathrm{PC}_{71} \mathrm{BM}$ blends 

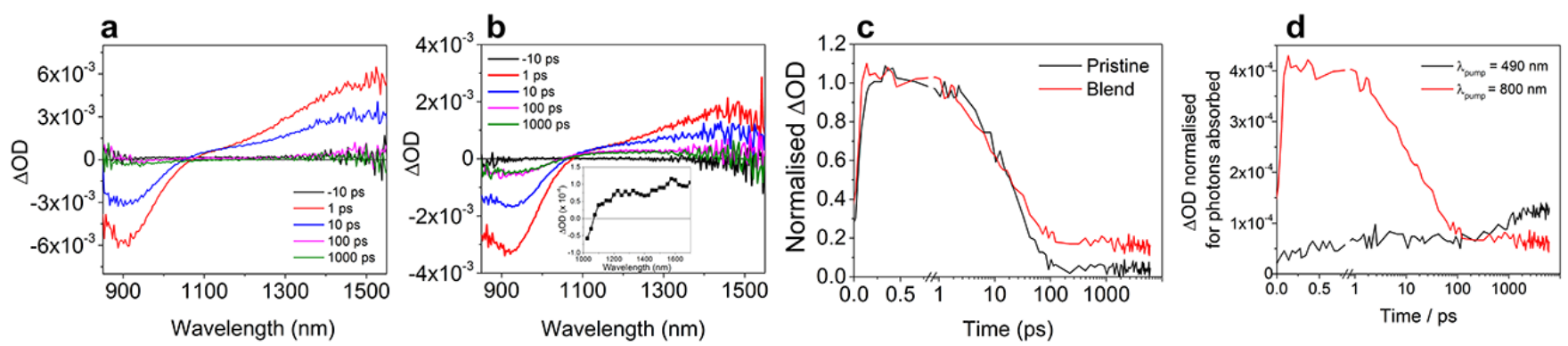

Figure 15. The fs-ps transient spectra of a) pristine INDT-S and b) INDT-S:PC7oBM (1:4), using a pump wavelength $\lambda_{\text {pmp }}=800$ nm with an excitation density of $6 \mu \mathrm{J} \mathrm{cm}^{-2}$. The inset shows the spectrum of the blend at $200 \mathrm{~ns}$ using a longer time resolution system. c) The normalised TA kinetics of the pristine and 1:4 blend films using $\lambda_{\text {pmp }}=800 \mathrm{~nm}, \lambda_{\mathrm{prb}}=950 \mathrm{~nm}$, with an excitation density of $2 \mu \mathrm{J} \mathrm{cm}^{-2}$. d) The TA kinetics of the INDT-S:PC 71 BM blend film using $\lambda_{\text {prb }}=950 \mathrm{~nm}$, with an excitation density of $2 \mu \mathrm{J} \mathrm{cm}^{-2}$, but varying the pump wavelength, $\lambda_{\mathrm{pmp}}=490 \mathrm{~nm}$ or $\lambda_{\mathrm{pmp}}=800 \mathrm{~nm}$.

To investigate this, femtosecond transient absorption spectroscopy (TAS) was performed on INDT-S:PC $\mathrm{C}_{71} \mathrm{BM}$ (1:4) blend films as a representative case (the respective INDT-T blend produced identical spectral trends). TAS results of pristine INDT-S (Figure 15a), pumped at the polymer absorption band at $800 \mathrm{~nm}$, reveal a broad band at approximately $1500 \mathrm{~nm}$ that decays with a time constant of 23 $\mathrm{ps}$, and is assigned to the polymer singlet exciton. Addition of the $\mathrm{PC}_{71} \mathrm{BM}$ to create the 1:4 blend film also leads to the formation of the polymer singlet exciton (Figure 15b). However, after the singlet exciton has decayed, a much longer-lived component is observed that absorbs from $1060 \mathrm{~nm}$ to above $1400 \mathrm{~nm}$. This component is still present when the INDT-S:PC $\mathrm{C}_{71} \mathrm{BM}$ blend transient spectrum is measured on ns- $\mu$ s timescales (Figure $15 \mathrm{~b}$ inset). Since no $\mathrm{O}_{2}$ sensitivity is observed, this long-lived component is assigned to polymer polarons.

The kinetics for both the pristine and blend films are shown in Figure 15c, using a pump wavelength of $800 \mathrm{~nm}$, thereby selectively exciting solely the polymer. It can be observed that the singlet exciton decay is largely complete by approximately $100 \mathrm{ps}$, leaving a signal of close to zero for the pristine film. For the blend film however, the longlived polymer polarons are evident after $100 \mathrm{ps}$ and they comprise approximately $17 \%$ of the initial signal amplitude. As such, most of the polymer excitons formed are lost through relaxation back to the ground state $(83 \%)$, which can be largely attributed to the lack of driving force for charge separation, although nanomorphology may also play a role. This is consistent with the polymer contribution to the EQE of approximately $20 \%$ at $800 \mathrm{~nm}$. Nevertheless, it is remarkable that such a high proportion of charge carriers are achievable through polymer excitation in ultra-low band gap polymers.

Observations when the fullerene is excited at $490 \mathrm{~nm}$ are quite different (Figure 15d) and suggest the presence of a second charge photogeneration mechanism. Upon excitation of the INDT-S:PC ${ }_{71} \mathrm{BM}$ blend at $490 \mathrm{~nm}$, no decay is observed at all. Instead, two separate rises in the ground state bleach signal are observed: the first from the initial time delay until approximately $100 \mathrm{ps}$, and the second from
100 ps until the end of the measured time range. These rises correspond to a steadily increasing concentration of polymer polarons in the blend film. The timescale of the second rise is consistent with hole transfer from the photoexcited fullerene to the polymer. This unusually slow nanosecond timescale hole transfer process has been previously observed in other polymers with low-lying LUMO levels. ${ }^{67}$ Since the appearance of this second rise coincides with the completion of the polymer exciton decay, the first rise for the INDT-S:PC $\mathrm{C}_{71} \mathrm{BM}$ blend can therefore be assigned to a combination of polymer exciton decay and hole transfer rise. The result of the slow rise in the polymer polaron concentration at this excitation wavelength is that by the end of the measured time range the percentage of polymer polarons present is approximately double that of solely polymer excitation when the polaron signals are normalised for number of photons absorbed. Again, this is consistent with the EQE results, which show a much greater contribution from $\mathrm{PC}_{71} \mathrm{BM}$ excitons compared to polymer excitons. We note that the high n-type mobility of the INDT based polymers may offer the potential for the use of this unit as an alternative to fullerene in organic solar cells. However, the extremely narrow band-gaps of this current generation of polymers prevents this possibility. Synthesis of wider band-gap, high n-type mobility materials with appropriately placed energy levels in currently ongoing.

\section{Conclusions}

We report a family of four extremely narrow band-gap polymers based on naturally occurring indigo with high thin-film crystallinity resulting in ultra-high n-type charge transport in OFETs. Electron mobility over $3 \mathrm{~cm}^{2} \mathrm{Vs}^{-1}$ was observed in benzothiadiazole copolymers, arising from a highly ordered polymer backbone. The extent of backbone crystallinity varied significantly as determined by GIWAXS and could be correlated with the electron mobility of the conjugated polymer. Theoretical analysis of the constituent units reveals that these polymers are in fact non-planar, yet extremely conformationally rigid due to a steric clash in their planar configurations. Despite the absence of 
planarity the obtained band-gaps are amongst the narrowest seen in conjugated polymers. Furthermore we demonstrate how commonly used co-monomer units can drastically affect backbone rigidity and hence charge carrier mobility. OPV devices using the novel materials gave PCEs up to $4.1 \%$ in OPVs with demonstrable photocurrent generation occurring at wavelengths up to $1000 \mathrm{~nm}$, while retaining good open circuit voltages. These results demonstrate the potential of this relatively unexplored chromophore in organic semiconductors as both an n-type transistor and a near-IR absorber in next generation organic electronic devices. Perhaps more importantly, these novel materials have allowed for a detailed understanding of the molecular origin of high n-type mobility in conjugated polymers. In particular, they demonstrate that planarity is not a requirement for ultra-high charge carrier mobility provided that the polymer backbone remains rigid. We anticipate the structure/optoelectronic relationships reported herein will contribute strongly to the bottom-up design of high mobility organic semiconductors.

\section{ASSOCIATED CONTENT}

\section{Supporting Information}

Detailed experimental procedures and characterizations for polymers and device fabrication procedures, measurements and additional figures and tables are available in the Supporting Information. This material is available free of charge via the Internet at http://pubs.acs.org.

\section{AUTHOR INFORMATION}

\section{REFERENCES}

1. He, Z.; Zhong, C.; Su, S.; Xu, M.; Wu, H.; Cao, Y., Enhanced Power-Conversion Efficiency in Polymer Solar Cells Using an Inverted Device Structure. Nat. Photon. 2012, 6, 591-595.

2. Zhang, Q.; Kan, B.; Liu, F.; Long, G.; Wan, X.; Chen, X.; Zuo, Y.; Ni, W.; Zhang, H.; Li, M.; Hu, Z.; Huang, F.; Cao, Y.; Liang, Z.; Zhang, M.; Russell, T. P.; Chen, Y., Small-Molecule Solar Cells with Efficiency over 9\%. Nat. Photon. 2015, 9, 35-41.

3. You, J.; Dou, L.; Yoshimura, K.; Kato, T.; Ohya, K.; Moriarty, T.; Emery, K.; Chen, C.-C.; Gao, J.; Li, G.; Yang, Y., A Polymer Tandem Solar Cell with 10.6\% Power Conversion Efficiency. Nat. Commun. 2013, 4, 1446.

4. Hamadani, B. H.; Gundlach, D. J.; McCulloch, I.; Heeney, M., Undoped Polythiophene Field-Effect Transistors with Mobility of 1cm2v-1S-1. Appl. Phys. Lett. 2007, 91, 243512.

5. $\quad$ McCulloch, I.; Heeney, M.; Chabinyc, M. L.; DeLongchamp, D.; Kline, R. J.; Cölle, M.; Duffy, W.; Fischer, D.; Gundlach, D.; Hamadani, B.; Hamilton, R.; Richter, L.; Salleo, A.; Shkunov, M.; Sparrowe, D.; Tierney, S.; Zhang, W., Semiconducting Thienothiophene Copolymers: Design, Synthesis, Morphology, and Performance in Thin-Film Organic Transistors. Adv. Mater. $2009,21,1091-1109$.

6. Wang, S.; Kappl, M.; Liebewirth, I.; Müller, M.; Kirchhoff, K.; Pisula, W.; Müllen, K., Organic Field-Effect Transistors Based on Highly Ordered Single Polymer Fibers. Adv. Mater. 2012, 24, 417-420.

7. Tsao, H. N.; Cho, D. M.; Park, I.; Hansen, M. R.; Mavrinskiy, A.; Yoon, D. Y.; Graf, R.; Pisula, W.; Spiess, H. W.; Müllen, K., Ultrahigh Mobility in Polymer Field-Effect Transistors by Design. J. Am. Chem. Soc. 2011, 133, 2605-2612. 
8. McCulloch, I.; Heeney, M.; Bailey, C.; Genevicius, K.; MacDonald, I.; Shkunov, M.; Sparrowe, D.; Tierney, S.; Wagner, R.; Zhang, W.; Chabinyc, M. L.; Kline, R. J.; McGehee, M. D.; Toney, M. F., Liquid-Crystalline Semiconducting Polymers with High Charge-Carrier Mobility. Nat. Mater. 2006, 5, 328-333.

9. Nielsen, C. B.; Turbiez, M.; McCulloch, I., Recent Advances in the Development of Semiconducting DPP-Containing Polymers for Transistor Applications. Adv. Mater. 2013, 25, 1859-1880.

10. Yuen, J. D.; Fan, J.; Seifter, J.; Lim, B.; Hufschmid, R.; Heeger, A. J.; Wudl, F., High Performance Weak Donor-Acceptor Polymers in Thin Film Transistors: Effect of the Acceptor on Electronic Properties, Ambipolar Conductivity, Mobility, and Thermal Stability. J. Am. Chem. Soc. 2011, 133, 20799-20807.

11. Li, Y.; Sonar, P.; Singh, S. P.; Zeng, W.; Soh, M. S., 3,6-Di(Furan-2-Yl)Pyrrolo[3,4-C]Pyrrole-1,4(2h,5h)-Dione and Bithiophene Copolymer with Rather Disordered Chain Orientation Showing High Mobility in Organic Thin Film Transistors. J. Mater. Chem. 2o11, 21, $10829-10835$.

12. Bronstein, H.; Chen, Z.; Ashraf, R. S.; Zhang, W.; Du, J.; Durrant, J. R.; Shakya Tuladhar, P.; Song, K.; Watkins, S. E.; Geerts, Y.; Wienk, M. M.; Janssen, R. A. J.; Anthopoulos, T.; Sirringhaus, H.; Heeney, M.; McCulloch, I., Thieno[3,2- B]ThiopheneDiketopyrrolopyrrole-Containing Polymers for High-Performance Organic Field-Effect Transistors and Organic Photovoltaic Devices. J. Am. Chem. Soc. 2011, 133, 3272-3275.

13. Lei, T.; Dou, J.-H.; Pei, J., Influence of Alkyl Chain Branching Positions on the Hole Mobilities of Polymer Thin-Film Transistors. Adv. Mater. 2012, 24, 6457-6461.

14. Mei, J.; Kim, D. H.; Ayzner, A. L.; Toney, M. F.; Bao, Z., Siloxane-Terminated Solubilizing Side Chains: Bringing Conjugated Polymer Backbones Closer and Boosting Hole Mobilities in Thin-Film Transistors. J. Am. Chem. Soc. 2011, 133, $20130-20133$.

15. Zhang, W.; Smith, J.; Watkins, S. E.; Gysel, R.; McGehee, M.; Salleo, A.; Kirkpatrick, J.; Ashraf, S.; Anthopoulos, T.; Heeney, M.; McCulloch, I., Indacenodithiophene Semiconducting Polymers for High-Performance, Air-Stable Transistors. J. Am. Chem. Soc. 2010, 132, 11437-11439.

16. Bronstein, H.; Leem, D. S.; Hamilton, R.; Woebkenberg, P.; King, S.; Zhang, W.; Ashraf, R. S.; Heeney, M.; Anthopoulos, T. D.; Mello, J. d.; McCulloch, I., Indacenodithiophene-Co-Benzothiadiazole Copolymers for High Performance Solar Cells or Transistors Via Alkyl Chain Optimization. Macromolecules 2011, 44, 6649-6652.

17. Zhang, X.; Bronstein, H.; Kronemeijer, A. J.; Smith, J.; Kim, Y.; Kline, R. J.; Richter, L. J.; Anthopoulos, T. D.; Sirringhaus, H.; Song, K.; Heeney, M.; Zhang, W.; McCulloch, I.; DeLongchamp, D. M., Molecular Origin of High Field-Effect Mobility in an Indacenodithiophene-Benzothiadiazole Copolymer. Nat. Commun. 2013, 4. 2238

18. Noriega, R.; Rivnay, J.; Vandewal, K.; Koch, F. P. V.; Stingelin, N.; Smith, P.; Toney, M. F.; Salleo, A., A General Relationship between Disorder, Aggregation and Charge Transport in Conjugated Polymers. Nat. Mater. 2013, 12, 1038 -1044.

19. Street, R. A., Unraveling Charge Transport in Conjugated Polymers. Science 2013, 341, 1072-1073.

20. Podzorov, V., Conjugated Polymers: Long and Winding Polymeric Roads. Nat. Mater. 2013, 12, 947-948.

21. Li, J.; Zhao, Y.; Tan, H. S.; Guo, Y.; Di, C.-A.; Yu, G.; Liu, Y.; Lin, M.; Lim, S. H.; Zhou, Y.; Su, H.; Ong, B. S., A Stable SolutionProcessed Polymer Semiconductor with Record High-Mobility for Printed Transistors. Sci. Rep. 2o12, 2, 754. 
22. Gruber, M.; Jung, S.-H.; Schott, S.; Venkateshvaran, D.; Kronemeijer, A. J.; Andreasen, J. W.; McNeill, C. R.; Wong, W. W. H.; Shahid, M.; Heeney, M.; Lee, J.-K.; Sirringhaus, H., Enabling High-Mobility, Ambipolar Charge-Transport in a DPP-Benzotriazole Copolymer by Side-Chain Engineering. Chem. Sci. 2015, 6, 6949-696o.

23. Park, J. H.; Jung, E. H.; Jung, J. W.; Jo, W. H., A Fluorinated Phenylene Unit as a Building Block for High-Performance N-Type Semiconducting Polymer. Adv. Mater. 2013, 25, 2583-2588.

24. Chen, Z.; Lee, M. J.; Shahid Ashraf, R.; Gu, Y.; Albert-Seifried, S.; Meedom Nielsen, M.; Schroeder, B.; Anthopoulos, T. D.; Heeney, M.; McCulloch, I.; Sirringhaus, H., High-Performance Ambipolar Diketopyrrolopyrrole-Thieno[3,2-B]Thiophene Copolymer Field-Effect Transistors with Balanced Hole and Electron Mobilities. Adv. Mater. 2012, 24, 647-652.

25. Sun, B.; Hong, W.; Yan, Z.; Aziz, H.; Li, Y., Record High Electron Mobility of $6.3 \mathrm{Cm}^{2} \mathrm{v}^{-1} \mathrm{~s}^{-1}$ Achieved for Polymer Semiconductors Using a New Building Block. Adv. Mater. 2014, 26, 2636-2642.

26. Kang, B.; Kim, R.; Lee, S. B.; Kwon, S.-K.; Kim, Y.-H.; Cho, K., Side-Chain-Induced Rigid Backbone Organization of Polymer Semiconductors through Semi-Fluoroalkyl Side Chains. J. Am. Chem. Soc. 2016, 138, 3679-3686

27. Dai, Y.-Z.; Ai, N.; Lu, Y.; Zheng, Y.-Q.; Dou, J.-H.; Shi, K.; Lei, T.; Wang, J.-Y.; Pei, J., Embedding Electron-Deficient Nitrogen Atoms in Polymer Backbone Towards High Performance N-Type Polymer Field-Effect Transistors. Chem. Sci. 2o16, 7, 5753-5757

28. Lei, T.; Dou, J.-H.; Cao, X.-Y.; Wang, J.-Y.; Pei, J., A Bdopv-Based Donor-Acceptor Polymer for High-Performance N-Type and Oxygen-Doped Ambipolar Field-Effect Transistors. Adv. Mater. 2013, 25, 6589-6593.

29. Zhao, Y.; Guo, Y.; Liu, Y., 25th Anniversary Article: Recent Advances in N-Type and Ambipolar Organic Field-Effect Transistors. Adv. Mater. 2013, 25, 5372-5391.

3o. Zhan, X.; Facchetti, A.; Barlow, S.; Marks, T. J.; Ratner, M. A.; Wasielewski, M. R.; Marder, S. R., Rylene and Related Diimides for Organic Electronics. Adv. Mater. 2011, 23, 268-284.

31. Fallon, K. J.; Wijeyasinghe, N.; Yaacobi-Gross, N.; Ashraf, R. S.; Freeman, D. M. E.; Palgrave, R. G.; Al-Hashimi, M.; Marks, T. J.; McCulloch, I.; Anthopoulos, T. D.; Bronstein, H., A Nature-Inspired Conjugated Polymer for High Performance Transistors and Solar Cells. Macromolecules 2015, 48, 5148-5154.

32. Gorner, H.; Pouliquen, J.; Kossanyi, J., Trans to Cis Photoisomerization of N,N'-Disubstituted Indigo Dyes Via Excited SingletStates - a Laser Flash-Photolysis and Steady-State Irradiation Study. Can. J. Chem.-Rev. Can. Chim. 1987, 65, 708-717.

33. Rondão, R.; Seixas de Melo, J.; Melo, M. J.; Parola, A. J., Excited-State Isomerization of Leuco Indigo. J. Phys. Chem. A 2012, 116, 2826-2832.

34. He, B.; Pun, A. B.; Zherebetskyy, D.; Liu, Y.; Liu, F.; Klivansky, L. M.; McGough, A. M.; Zhang, B. A.; Lo, K.; Russell, T. P.; Wang, L.; Liu, Y., New Form of an Old Natural Dye: Bay-Annulated Indigo (Bai) as an Excellent Electron Accepting Unit for High Performance Organic Semiconductors. J. Am. Chem. Soc. 2014, 136, 15093-15101.

35. He, B.; Neo, W. T.; Chen, T. L.; Klivansky, L. M.; Wang, H.; Tan, T.; Teat, S. J.; Xu, J.; Liu, Y., Low Bandgap Conjugated Polymers Based on a Nature-Inspired Bay-Annulated Indigo (Bai) Acceptor as Stable Electrochromic Materials. ACS Sustain. Chem. Eng. 2016, 4, 2797-2805. 
36. Tsai, C.-H.; Fortney, A.; Qiu, Y.; Gil, R. R.; Yaron, D.; Kowalewski, T.; Noonan, K. J. T., Conjugated Polymers with Repeated Sequences of Group 16 Heterocycles Synthesized through Catalyst-Transfer Polycondensation. J. Am. Chem. Soc. 2o16, 138, 6798-6804.

37. Vezie, M. S.; Few, S.; Meager, I.; Pieridou, G.; Dorling, B.; Ashraf, R. S.; Goni, A. R.; Bronstein, H.; McCulloch, I.; Hayes, S. C.; Campoy-Quiles, M.; Nelson, J., Exploring the Origin of High Optical Absorption in Conjugated Polymers. Nat. Mater. 2o16, advance online publication. doi:10.1038/nmat4645

38. Richards, T. J.; Sirringhaus, H., Analysis of the Contact Resistance in Staggered, Top-Gate Organic Field-Effect Transistors. J. Appl. Phys. 2007, 102, 094510.

39. Rentenberger, S.; Vollmer, A.; Zojer, E.; Schennach, R.; Koch, N., Uv/Ozone Treated Au for Air-Stable, Low Hole Injection Barrier Electrodes in Organic Electronics. J. Appl. Phys. 2006, 100, 053701.

40. Stadlober, B.; Haas, U.; Gold, H.; Haase, A.; Jakopic, G.; Leising, G.; Koch, N.; Rentenberger, S.; Zojer, E., Orders-of-Magnitude Reduction of the Contact Resistance in Short-Channel Hot Embossed Organic Thin Film Transistors by Oxidative Treatment of AuElectrodes. Adv. Funct. Mater. 2007, 17, 2687-2692.

41. Zhou, Y.; Fuentes-Hernandez, C.; Shim, J.; Meyer, J.; Giordano, A. J.; Li, H.; Winget, P.; Papadopoulos, T.; Cheun, H.; Kim, J.; Fenoll, M.; Dindar, A.; Haske, W.; Najafabadi, E.; Khan, T. M.; Sojoudi, H.; Barlow, S.; Graham, S.; Brédas, J.-L.; Marder, S. R.; Kahn, A.; Kippelen, B., A Universal Method to Produce Low-Work Function Electrodes for Organic Electronics. Science 2012, 336, 327-332.

42. Zaumseil, J.; Sirringhaus, H., Electron and Ambipolar Transport in Organic Field-Effect Transistors. Chemical Reviews 2007, 107, 1296-1323.

43. Horowitz, G., Organic Field-Effect Transistors. Adv. Mater. 1998, 10, 365-377.

44. Bolognesi, A.; Di Carlo, A.; Lugli, P., Influence of Carrier Mobility and Contact Barrier Height on the Electrical Characteristics of Organic Transistors. Appl. Phys. Lett. 2002, 81, 4646-4648.

45. Natali, D.; Caironi, M., Charge Injection in Solution-Processed Organic Field-Effect Transistors: Physics, Models and Characterization Methods. Adv. Mater. 2012, 24, 1357-1387.

46. Simonetti, O.; Giraudet, L.; Maurel, T.; Nicolas, J. L.; Belkhir, A., Organic Transistor Model with Nonlinear Injection: Effects of Uneven Source Contact on Apparent Mobility and Threshold Voltage. Org. Electron. 2010, 11, 1381-1393.

47. Giraudet, L.; Simonetti, O., Threshold Voltage and Turn-on Voltage in Organic Transistors: Sensitivity to Contact Parasitics. Org. Electron. 2011, 12, 219-225.

48. Bittle, E. G.; Basham, J. I.; Jackson, T. N.; Jurchescu, O. D.; Gundlach, D. J., Mobility Overestimation Due to Gated Contacts in Organic Field-Effect Transistors. Nat. Commun. 2016, 7. 10908

49. McCulloch, I.; Salleo, A.; Chabinyc, M., Avoid the Kinks When Measuring Mobility. Science 2016, 352, $1521-1522$.

5o. Yamashita, Y.; Hinkel, F.; Marszalek, T.; Zajaczkowski, W.; Pisula, W.; Baumgarten, M.; Matsui, H.; Müllen, K.; Takeya, J., Mobility Exceeding $10 \mathrm{Cm}^{2} /(\mathrm{V} \cdot \mathrm{S})$ in Donor-Acceptor Polymer Transistors with Band-Like Charge Transport. Chem. Mater. 2o16, 28, 420424 .

51. Smilgies, D.-M., Scherrer Grain-Size Analysis Adapted to Grazing-Incidence Scattering with Area Detectors. J. Appl. Crystallogr. 2009, 42, 1030-1034. 
52. Rivnay, J.; Toney, M. F.; Zheng, Y.; Kauvar, I. V.; Chen, Z.; Wagner, V.; Facchetti, A.; Salleo, A., Unconventional Face-on Texture and Exceptional in-Plane Order of a High Mobility N-Type Polymer. Adv. Mater. 2010, 22, 4359-4363.

53. Meager, I.; Nikolka, M.; Schroeder, B. C.; Nielsen, C. B.; Planells, M.; Bronstein, H.; Rumer, J. W.; James, D. I.; Ashraf, R. S.; Sadhanala, A.; Hayoz, P.; Flores, J.-C.; Sirringhaus, H.; McCulloch, I., Thieno[3,2-B]Thiophene Flanked Isoindigo Polymers for High Performance Ambipolar Ofet Applications. Adv. Funct. Mater. 2014, 24, 7109-7115.

54. Shahid, M.; McCarthy-Ward, T.; Labram, J.; Rossbauer, S.; Domingo, E. B.; Watkins, S. E.; Stingelin, N.; Anthopoulos, T. D.; Heeney, M., Low Band Gap Selenophene-Diketopyrrolopyrrole Polymers Exhibiting High and Balanced Ambipolar Performance in Bottom-Gate Transistors. Chem. Sci. 2012, 3, 181-185.

55. Ashraf, R. S.; Meager, I.; Nikolka, M.; Kirkus, M.; Planells, M.; Schroeder, B. C.; Holliday, S.; Hurhangee, M.; Nielsen, C. B.; Sirringhaus, H.; McCulloch, I., Chalcogenophene Comonomer Comparison in Small Band Gap Diketopyrrolopyrrole-Based Conjugated Polymers for High-Performing Field-Effect Transistors and Organic Solar Cells. J. Am. Chem. Soc. 2015, 137, 1314-1321.

56. Chen, Z.; Lemke, H.; Albert-Seifried, S.; Caironi, M.; Nielsen, M. M.; Heeney, M.; Zhang, W.; McCulloch, I.; Sirringhaus, H., High Mobility Ambipolar Charge Transport in Polyselenophene Conjugated Polymers. Adv. Mater. 2010, 22, $2371-2375$.

57. Venkateshvaran, D.; Nikolka, M.; Sadhanala, A.; Lemaur, V.; Zelazny, M.; Kepa, M.; Hurhangee, M.; Kronemeijer, A. J.; Pecunia, V.; Nasrallah, I.; Romanov, I.; Broch, K.; McCulloch, I.; Emin, D.; Olivier, Y.; Cornil, J.; Beljonne, D.; Sirringhaus, H., Approaching DisorderFree Transport in High-Mobility Conjugated Polymers. Nature 2014, 515, 384-388.

58. Jackson, N. E.; Savoie, B. M.; Kohlstedt, K. L.; Olvera de la Cruz, M.; Schatz, G. C.; Chen, L. X.; Ratner, M. A., Controlling Conformations of Conjugated Polymers and Small Molecules: The Role of Nonbonding Interactions. J. Am. Chem. Soc. 2013, 135, 1047510483.

59. Yan, H.; Chen, Z.; Zheng, Y.; Newman, C.; Quinn, J. R.; Dotz, F.; Kastler, M.; Facchetti, A., A High-Mobility Electron-Transporting Polymer for Printed Transistors. Nature 2009, 457, 679-686.

6o. Sommer, M., Conjugated Polymers Based on Naphthalene Diimide for Organic Electronics. J. Mater. Chem. C 2014, 2, 3088-3098.

61. Fazzi, D.; Caironi, M., Multi-Length-Scale Relationships between the Polymer Molecular Structure and Charge Transport: The Case of Poly-Naphthalene Diimide Bithiophene. PCCP 2015, 17, 8573-8590.

62. Kang, B.; Kim, R.; Lee, S. B.; Kwon, S.-K.; Kim, Y.-H.; Cho, K., Side-Chain-Induced Rigid Backbone Organization of Polymer Semiconductors through Semifluoroalkyl Side Chains. J. Am. Chem. Soc. 2016, 138, 3679-3686.

63. Caironi, M.; Bird, M.; Fazzi, D.; Chen, Z.; Di Pietro, R.; Newman, C.; Facchetti, A.; Sirringhaus, H., Very Low Degree of Energetic Disorder as the Origin of High Mobility in an N-Channel Polymer Semiconductor. Adv. Funct. Mater. 2011, 21, $3371-3381$.

64. Mooibroek, T. J.; Gamez, P., Anion-Arene and Lone Pair-Arene Interactions Are Directional. CrystEngComm 2012, 14, 1027-1030. 65. Christie, R. M., Why Is Indigo Blue? Biotechnic E Histochemistry 20o7, 82, 51-56.

66. Hendriks, K. H.; Li, W.; Wienk, M. M.; Janssen, R. A. J., Small-Bandgap Semiconducting Polymers with High near-Infrared Photoresponse. J. Am. Chem. Soc. 2014, 136, 12130-12136.

67. Dimitrov, S. D.; Huang, Z.; Deledalle, F.; Nielsen, C. B.; Schroeder, B. C.; Ashraf, R. S.; Shoaee, S.; McCulloch, I.; Durrant, J. R., Towards Optimisation of Photocurrent from Fullerene Excitons in Organic Solar Cells. Energy. Environ. Sci. 2014, 7, 1037-1043. 


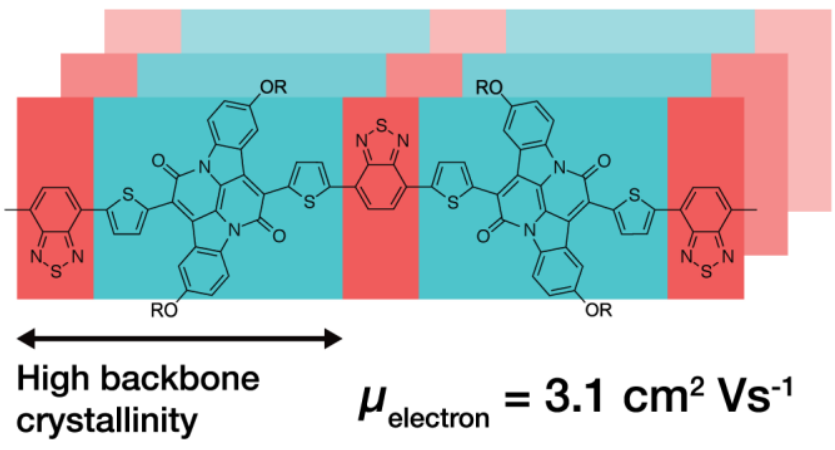

